\title{
Embodied Simulations of Forces of Nature and the Role of Energy in Physical Systems
}

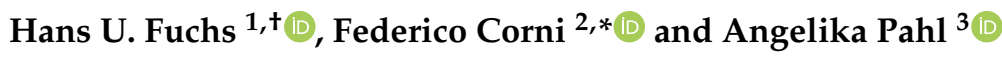 \\ 1 Institute for Applied Mathematics and Physics, Zurich University of Applied Sciences, \\ 8401 Winterthur, Switzerland; hans.fuchs@narrativescience.org \\ 2 Faculty of Education, Free University of Bozen-Bolzano, 39042 Bressanone, Italy \\ 3 Institute of Primary Education, University of Teacher Education Bern, 3012 Bern, Switzerland; \\ angelika.pahl@phbern.ch \\ * Correspondence: federico.corni@unibz.it \\ + Retired.
}

check for updates

Citation: Fuchs, H.U.; Corni, F.; Pahl, A. Embodied Simulations of Forces of Nature and the Role of Energy in Physical Systems. Educ. Sci. 2021, 11, 759. https://doi.org/10.3390/ educsci11120759

Academic Editor: Stephen A. Butterfield

Received: 19 August 2021 Accepted: 9 November 2021 Published: 24 November 2021

Publisher's Note: MDPI stays neutral with regard to jurisdictional claims in published maps and institutional affiliations.

Copyright: (c) 2021 by the authors. Licensee MDPI, Basel, Switzerland. This article is an open access article distributed under the terms and conditions of the Creative Commons Attribution (CC BY) license (https:/ / creativecommons.org/licenses/by/ $4.0 /$ )

\begin{abstract}
We experience (perceive, act upon and react to, and conceptualize) dynamical processes in nature as agentive. Expressed differently, we experience events as resulting from activities and interactions of Forces of Nature (such as wind, light, heat, fluids, electricity, substances, and motion) that are conceived of as powerful agents acting and interacting in physical environments. An example would be sunlight creating heat in the Earth's surface layers, and this heat using the atmosphere as a heat engine whose output are the winds on our planet. In the physics of dynamical systems, these forces are characterized in terms of intensive and extensive quantities (i.e., electric potential and electric charge in the case of electricity). The aspect of power is formalized with the help of a generalized energy principle and the rules relating power/energy to intensive and extensive physical quantities. Concrete processes depend upon properties of physical materials (in and through which forces are active) such as (thermal, electrical, etc.) capacity or conductivity. In this paper, we demonstrate how we can create Embodied Simulations and Forces-of-Nature Theater performances, where children act as forces such as water, heat, electricity, and motion. The embodied logic of the physical play teaches children about the logic of our explanations of physical processes.
\end{abstract}

Keywords: physics education; embodied mind; image schema; metaphor; simulation and play; energy; forces of nature

\section{Introduction and Overview}

In this introduction, we present an overview of issues to be presented and discussed in the following sections. First, however, we briefly outline claims to be argued for and goals to be followed.

\subsection{Claims and Aims}

We claim that, in direct physical experience of natural and technical scenes, and supported by narrative practices [1], we create the concept of Force-of-Nature (FoN) [2-4]. This concept is central to macroscopic physical science-continuum physics and the physics of dynamical systems, which we use as scientific bases of our approach [5-10] - that produces theories of forces we call fluids, electricity and magnetism, gravity, heat, substances, and (linear and rotational) motion [10]. Furthermore, understanding of Forces of Nature-their characteristics and activities - makes use of embodied (imaginative, figurative) mental tools that arise in organism-environment couplings [11]. Such understanding is expressed with the help of different "media", such as natural language, play, drawings, mime and theater performances, and, very importantly, stories told about events in nature and machines.

This brings us to a central claim: if our mind gives us the notion of FoN plus the abstract mental tools for understanding them, and if FoN are central to formal science, we 
should be able to learn about nature and machines in a manner that prepares us, while we are young, for at least some basic experiential and conceptual aspects of later engagements with this formal science.

We can put the aim(s) we pursue with our theme as follows. While explorations of nature and technical systems and formal instruction are staples of education, other "media" through which we may gain access to our subject are less well established. For this reason, and because we believe that necessary concepts for physical science are embodied, we have been investigating how our bodies might be used for learning about FoN, their characteristics and actions in physical systems. This paper is an outline of scientific, cognitive, and practical aspects and work that has gone into the production of Embodied Simulations (ES) and Forces-of-Nature Theater (FoN-T) performances (see also [12,13]).

\subsection{Forces of Nature}

Forces of Nature $[2,3,12,14-16]$ constitute a category of phenomena we experience as agentive and powerful (see Section 2.1). Examples of FoN are wind and rain, water and air, heat and electricity, food and medicines, and gravity and motion. In everyday life, the category is somewhat fuzzy-we spontaneously create the notion for systems and processes that may be of only passing interest-whereas in physical sciences, it is well defined and encompasses only a small number of forces: fluids, heat, electricity and magnetism, transport and reaction of substances, gravitation, and rotational and linear motion. Forces (which must be distinguished from "forces" in mechanics; we make this distinction clear in the text by capitalizing Force and using italics when used in the sense of FoN) are all characterized by the same small number of abstract aspects (intensity, extension, and power) that allows us to apply analogy to their representations.

\subsection{Imagination and Figurative Thought}

Importantly, fundamental abstractions and conceptual elements of formal physical science coincide with everyday cognitive structures that arise in organism-environment couplings and rise to consciousness by individual acts of imagining and imaginative forms of joint activity and communication (see Section 2.2). Our use of schematic structures with their metaphoric and analogical projections applied in larger narratives mostly parallels the figurative structures in macroscopic physics $[10,17,18]$. This suggests that an embodied imaginative, i.e., schematic, metaphoric, analogical, and narrative, approach to natural and technical systems and processes is not only possible but essential if we wish to understand important aspects of our experience of physical phenomena.

Suggesting that a "narrative, approach [ ... ] is [ ... ] essential" to scientific work may raise a number of questions concerning the nature of science and epistemology. We may ask "[is this approach] not excessively biased in the linguistic and narrative analysis? It gives the feeling that science is "a way of narrating or speaking" just as valid as others (for example: religion)." (This point has been raised by an anonymous reviewer.) It is clear that (formal) science is more than can be based upon a narrative approach alone; there are many more aspects to the practice and the products of science. However, it has been demonstrated quite clearly that narrative is not just a means of speaking about science but, very importantly, a tool for doing science. Based on work by Wise [19] on simulation of complex systems and processes and Morgan $[20,21]$ on modeling in economics, the use of narrative has been extended to include conceptual work in the sciences [17]. Actually, the point is even stronger: production and use of science are narrative affairs. Continuum physics presents us with clearly visible narrative structures [10]. When scientists and engineers produce simulations, they are effectively telling narratives that let them understand the conceptual structure of the underlying models (this is similar to when reading a novel lets us create mental model-worlds that allow us to understand characters and their actions; the analogy between simulations and models on the one hand, and stories and story-worlds on the other has been introduced by Fuchs [17]). Moreover, the use of stories of Forces of Nature in primary education is a tool for giving the hearer (or reader) a chance at narrative 
experience paralleling direct physical experience which, it is hoped, in their combination lead to conceptual understanding. See, in particular, Section 2.2 of our paper.

\subsection{Energy in Physical Systems and Processes}

The foregoing should make it clear that we do not aim at adding to the issue of how to teach physics in general and the energy principle in particular, in standard formal physics courses. However, since some of the activities described here afford an embodied approach to energy, we should discuss how traditional ways of dealing with energy in physics courses, and in Physics Education Research (PER) underlying them, stack up against what we propose here (Section 2.3).

\subsection{Embodied Simulations}

In recent years, we have created designs for ES and FoN-T performances for young learners to combine direct physical experience of $\mathrm{FoN}$ in natural and technical settings with narrative experience, i.e., with particular forms of communicative activity between themselves and teachers who jointly attend to phenomena (Sections 3 and 4; $[12,16])$. ES (see Section 3) can be used to represent storage and flow (and production/destruction) of extensive quantities related to tension (i.e., differences of potentials). Simple and analogous examples would be filling and simultaneous discharging (through a horizontal pipe at the bottom) of a water tank (Section 3), heating and simultaneous cooling of water in an open pot on a stove and charging and discharging of an electric capacitor. In the second example, the case of heating, heat-as-substance (entropy) flows from the stove into the water, is stored there and leads to thermal tension, whereupon it flows out again, driven by this tension and obstructed by the walls of the pot.

Note that, like any other basic phenomenon, heat admits an extensive quantity, i.e., a quantity of heat that resides in bodies (making them warm and causing a couple of other changes such as letting them expand), is capable of flowing into and out of bodies, and can be produced such as when we rub our hands or make a fire. In other words, in our imagination, we all make use of the idea of a fluidlike quantity of thermal processes we call "heat" when communicating in every-day life. This is what a child or lay-person means when they use the noun "heat." When drinking hot chamomile tea, the five-year old grandson of one of the authors said, "I like the heat for my body so I can be warmer the next day." When eating carrots for lunch that had gotten cold, he was asked where the heat was that had made the carrots hot; his response: "it is now out of the carrots." Unfortunately, Traditional Equilibrium Thermodynamics (TET) [22] does not present us with a ready-made extensive quantity of heat. What is defined as "heat" in TET is not(!) an extensive quantity: engineers know that there is no "heat" content in their theory, and physicists say that "heat" is not a state-function. However, in TET, there is an indirectly constructed quantity that, if generalized as in Continuum Thermodynamics (CT) [7] and a Dynamical Theory of Heat (DTH) [8], has all the properties of the extensive quantity of heat: it is what is called entropy in the extended modern theories (CT and DTH; see [23]). Interestingly, physicists and engineers only versed in TET are usually unaware that entropy serves as the extensive thermal quantity (in TET, entropy is a severely restricted version of the general idea of entropy as an extensive quantity of heat). All this leaves laypeople at a great disadvantage: their simple imaginative (and scientifically correct!) idea of an extensive quantity of heat, which they simply call "heat," is disallowed in traditional scientific discourse. Being asked to call what they know and understand as "heat" by the mad-up word "entropy" is like calling water "hydropy," or giving it some other made-up name-it kills any chance a layperson might have had at understanding thermal processes [24]! Faced with this dilemma, we shall be writing entropy for the extensive fluidlike quantity of thermal phenomena; but we kindly ask readers who are not formally trained physicists, chemists, or engineers to choose one of the following words when they encounter entropy in our text-heat, quantity of heat, heat substance, thermal charge [25], or caloric - to help them make sense of what is actually meant. [Caloric, derived from the Latin 
calor, is the term for quantity of heat used some 200 years ago in the Caloric Theory of Heat (CTH). Calorists mostly considered caloric a "quasi-material" fluid and therefore had all sorts of special ideas about "material" and "mechanical" properties of this fluid [26]. However, when they made calculations for applications such as theories of sound or heat engines, they effectively only made use of basic schematic aspects [23]: caloric resides in bodies to make them warm or let them expand, and it flows into or out of these bodies. However, they assumed that caloric had to be conserved in all processes. If we take a modern approach, we add to the calorists' schematic aspects the assumption that caloric will be produced in irreversible processes such as friction and burning of fuels. In this form, caloric equals the entropy of CT and DTH (see [27-30])].

Entropy (heat-as-substance) would be represented by children crowding into an area-designated as the water in the pot; tension rises as the density of children inside the area rises; and outflow (heat loss) is symbolized by children leaving the area at a rate proportional to the tension. The analogy between hydraulic, thermal, and electric examples, and the role played by children in the case of heating of water, tell us that entropy (heat-assubstance) and electric charge (electricity-as-substance) are analogous to amount of water. Importantly, quantity of heat and quantity of electricity are not identified with energy!

\subsection{Forces-of-Nature Theater and Energy}

FoN-T performances are a more sophisticated representation of Forces of Nature acting and interacting, that includes a physical representation of energy (see Section 4). Take, as a simple example, a steady state model of an electric water pump with electric charge flowing through the device from a high to a low electric potential (level), and water being forced (pumped) through the device from low to high pressure. As before, a group of children models a particular FoN, which means that we need at least two groups representing electricity and water, respectively. Potentials (intensities) are symbolized by bodily expression of tension/relaxation. Energy is represented by some material, such as confetti, that is carried by and exchanged between the groups of children. As some of the confetti handed by a child of the electricity group to one of the water group falls to the floor, it can be picked up and carried away by kids of a third group that come "out of nowhere" - they represent entropy (heat-as-substance).

\subsection{Summary and Outlook}

Finally, in Section 5, we shall describe didactic aspects of using the activities proposed here in the classroom. We shall summarize practical experience, generally important points regarding imaginative and activity-based learning, and suggest research that still needs to be conducted in this exciting field of STEM pedagogy.

\section{Forces of Nature in Macroscopic Physics and Cognitive Science}

Forces of Nature such as wind, light, heat and cold, electricity, chemicals, and motion are the protagonists of our theme. For this reason, we shall describe what we mean by the term FoN, and show how, on the one hand, the idea fits into macroscopic physics (Section 2.1) and, on the other, they arise in basic experience and what this means for conceptualization and communication (Section 2.2). In a nutshell, we claim that what is a backbone of formal macroscopic physical science (in the form of continuum physics and theories of uniform dynamical systems) has its root in fundamental, everyday abstractions we create as a result of our embodied interaction with our physical and social environments, i.e., as we grow up and learn about the world around us.

For educational purposes, we distinguish between primary Forces of Nature that arise in our mind through direct encounters with natural and technical phenomena, and basic Forces which form a sub-category that is formalized in macroscopic physical science. Importantly, we will see that different forces are all treated analogously by our mind-we always make use of the same small number of schemas and metaphoric projections in presenting the Forces to ourselves in acts of imagining. 


\subsection{Characteristics of Forces of Nature and Analogical Structures}

\subsubsection{Primary Forces of Nature}

In our encounters with nature and technical artifacts, we experience events (dynamical processes) as caused by Forces of Nature [2,3]. We take the term FoN from how it has always been applied to environment-shaping forces such as wind, water, ice, fire, volcanoes, and the geologically primary force of continental drift. However, it is quite common to speak of Forces (of nature) in other cases as well. Note that this is a historically primary use of the word Force and has to be distinguished clearly from the concept of force in mechanics. A pre-scientific list of primary Forces of Nature includes wind, light, fire, rain, water, air, heat and cold, lightning and magnets, soil, plants, food, medicines, gravity, and motion. The sense of these forces is created by everyday encounters with our physical environment mediated by tensions which we associate with certain polarities (see Section 2.2).

These forces all share a few basic characteristics. As mentioned, they arise from our sense of intensity —rain, light, fire, etc., can all be more or less intense. Furthermore, they are spatially extended: light "floods" a room, fire "covers" a hillside, and rain "moves into" a valley. Naturally, intensity and extension change in the course of time, placing Forces at the center of dynamics and natural history. Finally, in a combination of these two traits, a Force is more or less powerful, i.e., it is more or less efficacious in causing certain outcomes. In other words, Forces are perceived as causal agents.

Observing that we associate the same fundamental abstractions with different phenomena is the source of a form of analogical reasoning that can be applied to our understanding of FoN and will prove invaluable in pedagogy and didactics.

\subsubsection{The Scientific Category of Basic Forces of Nature}

Macroscopic physics-in the form of either spatially continuous or spatially uniform dynamical models [8] — deals with fields usually termed fluids, electricity and magnetism, heat, transport and reaction of substances, gravitation, and rotational and linear motion (see Table 1). In their most general forms, these theories apply analogy in the form of structure mapping [31] between fields to their models [8,32] (see also [7,9] on continuum thermodynamics). For example, the flow of blood in our bodies can be represented in terms of dynamical electric circuits [8] (Chapter 1), and the "motive power of heat" [33] can be compared to the gravitational power of a waterfall.

Table 1. Fields of macroscopic physics as basic Forces of Nature.

\begin{tabular}{ccc}
\hline Field (Force of Nature) & Extensive Quantity & Intensive Quantity \\
\hline Fluids & Volume & Pressure \\
\hline Electricity (and magnetism) & Charge & Electric potential \\
\hline Heat & Entropy & Temperature \\
\hline Chemical processes & Amount of substance & Chemical potential \\
\hline Gravitation & Gravitational mass & Gravitational potential \\
\hline Linear (translational) motion & Momentum & Velocity \\
\hline Rotational motion & Spin (angular momentum) & Angular velocity \\
\hline
\end{tabular}

In the physics of dynamical systems, these Forces are characterized in terms of intensive and extensive quantities [8]. Examples of intensities are pressure, electric potential, and temperature in the cases of fluids, electricity, and heat, respectively; the extensive quantities associated with these Forces are fluid volume, electric charge, and entropy. The aspect of power is formalized with the help of a generalized energy principle and the rules relating power/energy to intensive and extensive physical quantities. For example, the power of heat (Sadi Carnot's expression [33]) is determined by the product of a temperature difference and the current of entropy (in Carnot's terms: the current of heat or caloric) through 
this temperature difference. Concrete processes depend upon properties of physical materials (in and through which forces are active), such as (thermal, electrical, etc.) capacity or conductivity. For example, the current of electric charge through a conductor depends upon conductivity and electric potential difference (and the geometry of the conductor).

The structure of theories of macroscopic physics lends itself to highly schematic, metaphoric, and analogical representations. Such representations include initial value problems in dynamical models and process diagrams that allow us to visually represent chains of processes (see Sections 3 and 4; [8,13,34]).

The scientific (basic) Forces of Nature are presented with mathematical formalisms that make it easy - for someone educated in these forms - to see, manipulate, and discuss logical structures. However, it is important to augment the scientific list of basic forces with that of primary forces, since the latter are primary in direct physical experience. For a pedagogy of Primary Physical Science [12,16], we need to take a perspective that allows us to deal with such primary experience of lay persons (adults and children alike).

\subsubsection{Analog Characteristics of Forces of Nature}

The reason why different FoN can be discussed in highly similar forms can be found in structures of our embodied mind: we use highly similar metaphoric projections of basic cognitive schemas when we talk (both informally and formally) about macroscopic physical systems and processes (see Section 2.2 for more detail). In each field (fluids, electricity, heat, etc.), we introduce an extensive quantity (see Table 1) which we imagine as fluidlike (these quantities satisfy laws of balance involving stored amounts, transports, and, in some cases, production and destruction, see [8]). Moreover, in each field, we introduce an intensive quantity or potential whose differences are experienced as tensions; these tensions are related to processes involving the fluidlike quantities. For example, when there is a pressure difference in the blood across the aortic valve (higher pressure in the left ventricle of the heart than in the aorta), the valve opens and blood flows; pressure difference and flow are related to each other by the concrete material situation presented to the blood by the passage from the ventricle into the aorta and by the properties of the blood.

Finally, each field admits the quantity we call energy as a concept arching over all of the fields and having the same relationship, with extensive and intensive quantities in each realm; that is why we do not list it separately in Table 1 . The energy principle provides for a separate conceptual layer above or below what we have in Table 1 ([8], Chapter 2).

To give an example, when entropy (i.e., heat-as-substance) "falls" from (absolute) temperature $T_{1}$ to $T_{2}$, it makes energy available at the rate $\left(T_{1}-T_{2}\right) \cdot I_{S}$ (where $I_{S}$ is the current of entropy; this is Carnot's waterfall image of processes representing interactions of Forces of Nature ([8] Chapter 4, [33]); when entropy flows conductively at (absolute) temperature $T$, it "carries" an energy current equal to $T \cdot I_{S}$; when entropy is produced at temperature $T$, energy is used at the rate $T \cdot \Pi_{S}$ (where $\Pi_{S}$ is the production rate of entropy). Analogical relations hold for electric, hydraulic, chemical, gravitational, and mechanical processes (production applies only to thermal and chemical phenomena). Note that the strict analogy governing the energy relations breaks down for convective and radiative transports. In these cases, the quantity of energy transported depends on the amount of energy stored either in fluids or radiation, which depends on the particular physical properties of these materials ([8], Chapters 7 and 8).

\subsubsection{Dynamical and Steady-State Models of Systems and Processes}

The activities of forces in natural and technical systems are worked out in models and simulations. Creating mathematical (computer) models and simulating them constitutes one of the most fundamental methodologies of modern science. It is important for us to note that modeling and simulation can also occur in informal pre-scientific work. We have demonstrated elsewhere that we can look upon this methodology as narrative: models are story-worlds (the worlds experienced when hearing or reading a story) and simulations are concrete stories told against the backdrop of a model/story-world [17]. For our 
present purpose; it makes sense to distinguish between two situations: fully dynamical activities (where quantities vary in the course of time) and steady-state processes (where the quantities of interest stay constant in time but processes nevertheless proceed).

The simplest dynamical models occur when we need to consider only a single force acting (see the formal example discussed in Section 3.1). Examples of events of interest are filling and draining of a water reservoir or our aorta (where the only Force of immediate concern is either water or blood as a fluid), heating of milk on a stove (where, if we are interested in the temporal run of temperature, the only important Force is heat), charging and discharging of an electric capacitor (where the Force of interest is electricity), or falling of a ball in air (where the only Force of interest is linear motion).

All we need for understanding one of these situations is a grasp of the characteristics of the Force in question (intensities, tensions, amounts, and flows) and its relation to the concrete material scene where it is active. Note that energy is not mentioned. Indeed, ever since Newton's example of how to model the motion of a body in a gravitational field, we know how to create descriptions based upon the characteristics of the Force that creates the dynamics we are interested in.

In most situations of interest in nature and engineering, systems are usually compound, and more than a single Force will be active. In fact, FoN will interact, both in chains and in parallel. (In real interactions, a thermal phenomenon-the production of entropy-will be caused in parallel to whatever process is brought about by a causing FoN.) An example of this kind is the pumping of water from a low-lying reservoir into a higher one with the help of a pump that is driven by an electric motor (see Section 4.1). Here, electricity interacts with rotation and heat in the motor, and rotation interacts with water and heat in the pump. Here is an important point: as soon as we consider interactions of Forces, we need to make use of the energy principle.

Dealing with such examples in fully dynamical situations is not difficult if we have the formal tools for working scientifically. However, in an informal, pre-scientific setting, we are better served if we consider just steady-state operations of the interactions of FoN. How this is done imaginatively - both in science and informally-with the help of process diagrams will be demonstrated by example in Section 4.1.

Actually, it would be possible to create a single combined representation of systems and processes, by either including dynamical aspects in process diagrams or extending dynamical models to the interaction of several FoN (which requires the consideration of energy). However, for practical and didactic reasons, it makes sense to divide the labor of explaining different aspects of physical processes between (simple) dynamical models and (more complex) steady-state representations as process diagrams. This division of labor will be carried over to the ES and FoN-T performances discussed in this paper (see Sections 3 and 4).

\subsection{Experiencing and Imagining Forces of Nature}

In the Introduction, we have briefly alluded to the central thesis of this paper: that various acts of imagining make our understanding of encounters with Forces of Nature possible and lay the foundation for conceptual development necessary for formal physical science. These acts of imagining - in the form of mental visualizations, metaphorical projections of basic schematic structures, analogical reasoning, and narrative understanding - come to us naturally in everyday life, and they come to us when we are still very young. In other words, fundamental abstractions and conceptual elements of formal physical science coincide with everyday cognitive structures. This should definitely not be taken as suggesting that understanding of, working in, and creating a formal science will effortlessly grow out of common sense and everyday thought. What we do want to say, however, is this: (1) a science such as physics is an imaginative affair, and (2) the most basic imaginative structures necessary (but not sufficient) for such a science will be found in everyday thought as well.

In this sub-section, we turn to aspects of embodied imaginative structures relevant to our designs of pedagogy, show how these structures apply to our understanding of the 
properties and activities of FoN in natural and technical settings, and demonstrate how schematism, metaphor, analogy, and storytelling have been combined by M. Deichmann in an animated story of an inventor wanting to create the "best invention ever-the perpetuum mobile, a machine that powers itself" [35]. Deichmann's animation will be the source of inspiration for FoN-T performances (see Section 4).

\subsubsection{The Origin of the Notion of Force of Nature in Experience}

From a naturalistic perspective, our experience of organism-environment interactions starts with the perceptions of tensions, i.e., differences of intensities or qualities. Intensities and qualities and their differences are rendered schematic as polarities such as light $\Leftrightarrow$ dark, hot $\Leftrightarrow$ cold, fast $\Leftrightarrow$ slow, concentrated $\Leftrightarrow$ diluted, and stressed $\Leftrightarrow$ relaxed. We may argue that even our visual and tactile senses that seem to present our mind directly with a notion of material objects start with the sense of (visual and tactile) tensions or polarities (hard $\Leftrightarrow$ soft, straight $\Leftrightarrow$ curved, shiny $\Leftrightarrow$ dull, heavy $\Leftrightarrow$ light, etc.). Since we know the feeling of tension from our forceful encounters with other people, we seem to create an analogy between our experience of such social encounters and encounters with natural phenomena and events. This, in our mind, creates a sense of agency associated with natural processes-hence our concept of FoN.

\subsubsection{Embodied Imaginative (Figurative) Structures}

In our approach, we make use of some of the most recent advances in cognitive science, particularly in cognitive linguistics and narratology (to the extent that they have been based on models of embodied mental structures). Here is a brief summary of the approach. We identify (image) schematic structures that originate in our sensorimotor interactions with our different environments. Image schemas [36,37] are experiential gestalts that originate in recurring embodied experience of our interactions with our various worlds (social, cultural, natural, etc.). Examples that are particularly important for our purpose are SCALE (which allows us to schematize experience of polarities such as hot-cold, light-dark, etc.), VERTICALITY (applied to concepts of intensities and qualities), TENSION, (FLUID) SUBSTANCE, FLOW, CONTAINER, PATH, AGENCY, PROCESS, CYCLE, FORCE, POWER, and many more. These image schemas are projected metaphorically upon our rich experience, covering a multitude of different social, psychological, cultural, and physical phenomena. In conceptual metaphor theory [3,38-43], metaphors are understood as unidirectional projections of structure or knowledge from a source domain to a target domain. Examples of basic conceptual metaphors where image schemas are projected are SOCIAL STATUS IS A VERTICAL SCALE (exemplified by expressions, such as "she has a high social status"), SUBSTANCES ARE CONTAINERS FOR HEAT (the water in the boiler contains a lot of heat), ELECTRICITY IS A FLUID SUBSTANCE (let electricity flow through this wire), MEDICINES ARE POWERFUL AGENTS (the painkiller made me feel better very quickly), etc.). Moreover, if a certain recurring group of metaphors is used for understanding different phenomena, these phenomena attain a degree of similarity in our mind which allows us to apply analogical reasoning when communicating about them. On analogy as structure mapping, see [31]. Since the same basic image schemas are used in metaphoric language to speak about phenomena such as heat and electricity, these phenomena become similar in our mind [18]. In thermal engineering it is quite common to use electric circuit models in order to compute heat transfer.

In narratives of forces acting and interacting over time in a given physical or social setting, we make use of these embodied imaginative structures [17,44]. Metaphors are embedded in the narrative flow of stories, which helps to us understand their meaning more profoundly than if they occurred separated from a larger context. Put differently, stories can transport us into story-worlds (i.e., mental models) where we narratively experience what otherwise could be a direct physical (embodied) experience [45].

In recent years, we have demonstrated that what has been highlighted by cognitive science about our imaginative understanding of everyday experience carries over, to a deep 
and important extent, to formal physical science. Physical theories are figurative- they make use of schematic, metaphoric, and analogical structures [2]. Importantly, we have demonstrated that narrative plays a fundamental role in modern scientific practice [10]. There exists an analogy between narrative and modeling and simulation: models are like story-worlds, and narratives (stories) are like simulations. In other words, a simulation is like a story told against the backdrop of the model that is simulated [17,46].

Applied to our context, this means that it is possible to tell stories of Forces of Nature that help learners make sense of their physical encounters with nature and machines. This gives us the motivation for searching for imaginative approaches to learning by designing embodied activities which create forms of experience paralleling direct physical and narrative experience.

Note that, while we frequently use (natural) language when we communicate our imaginative understanding of natural and other phenomena, language is not our only tool. We can express schemas, metaphors, analogy, and stories in a number of different "media", such as drawings (see the process diagrams in Section 4), film [35], gesture, mime and theater performances, and music. This tells us that there are, for example, visual or gestural metaphors whose concrete renderings are analogous to linguistic metaphoric expressions. Moreover, a theater performance usually tells a story. In the following, we shall make use of these observations.

\subsubsection{Imaginatively Structuring Forces of Nature}

The way we imaginatively render our experience of the natural world is central to our claim how we can learn about natural (and technical) systems and processes. The following short list shows which examples of imaginative structures are needed for our approach to learning about Forces of Nature.

Since experience allows us to conceptualize a FoN as having aspects of intensity (and its differences, i.e., tensions), extension (quantity or (fluid) amount associated with storage, flow, production and destruction), and power, all we need for communicating about a force are schemas and metaphors that fit and support our understanding of these aspects. Since we want to discuss embodied renderings of Forces acting in natural and technical systems, we can say directly how the necessary schemas and their metaphoric projections can be expressed with the help of our bodies and possibly some props. Intensity and tension (such as temperature, pressure, and temperature and pressure differences) can be expressed by bodily and facial demeanor (tensed-relaxed, active-inactive, awake-sleepy, etc.). Amount of a fluidlike quantity (the extensive aspect of a force) can be represented by bodily size or, more easily, by the number of actors in a performance (a current will be expressed by the flow of actors on a stage).

Energy comes into play most basically when two FoN interact. One way the interaction of two agents has been discussed in cognitive science is to say that (1) we have an agent and a patient, and (2) the agent "gives something" to the patient, which is a metaphorical form of representing the interaction (examples: he gives me a headache). This opens a very simple way for us to represent energy: energy is what is passed (exchanged) between a FoN that drives a phenomenon (agent) and the driven or caused force (patient). In an embodied performance of such an interaction, we simply use a prop that can easily be handed from agent to patient (and, naturally, can be first carried to the scene by the agent and then carried away by the patient).

\subsubsection{An Animated Story of Interacting Forces of Nature}

An animated story of a perpetuum mobile [35] provides an imaginative approach to Forces of Nature and their relation to energy [47]. The animation tells the story of an inventor who dreams of the perfect perpetual motion engine (Figure 1a) consisting of a light bulb, solar cell, electric water pump, water wheel, and generator. A first push of the generator lets the bulb burn, which makes the solar cell work, which drives the pump. The water pumped drives the wheel which drives the generator, and so on, in circular "motion". 

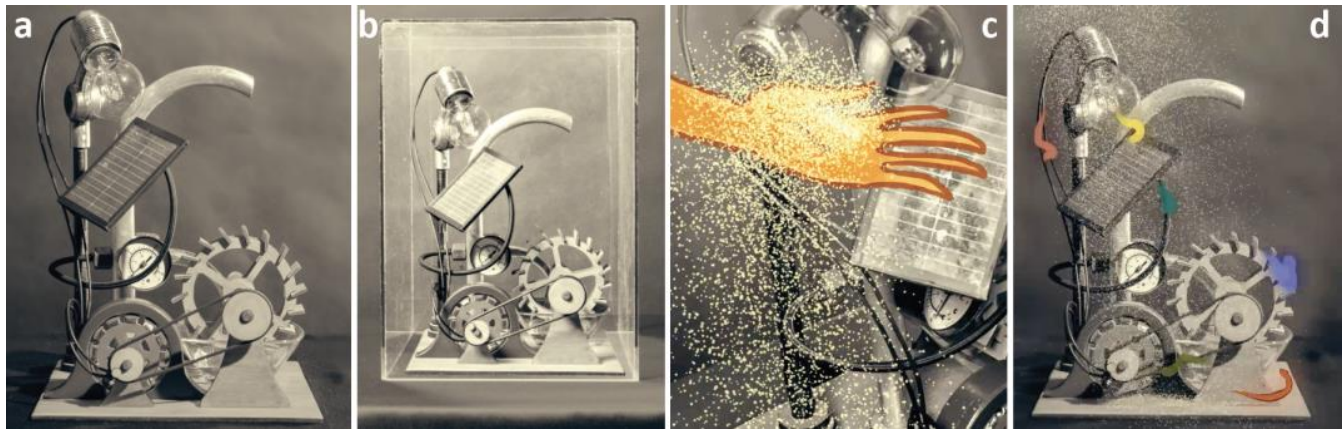

Figure 1. The inventor's perpetual motion machine (a). When it does not work, it is put under a glass cover in a museum (b). Sunlight (the golden hand representing the rays of the Sun) make energy (dust) available (c). When the engine finally operates in steady-state, little spirits (representing FoN) are responsible for the operations $(\mathbf{d})$. The material parts of the engine have become the ground upon which the FoN act. (Stills are taken from Deichmann's animation [35]).

Naturally, this machine will never work. It is put in a museum under a glass cover (Figure 1b). By chance, the light of the sun strikes the solar cell (Figure 1c). The machine starts working, heat is produced in all its operations, the glass cover explodes, and the machine is set free to work in an open flow system (Figure 1d).

To understand what is happening, we need to perform a couple of imaginative acts. First of all, we need to let the (material parts of the) machine recede into the background whereupon we can "see" in our minds eye how agents appear and operate. These agents represent FoN: light, electricity, water, rotational and linear motion, and heat. Deichmann [35] presents these agents as figures, as little spirits (Figures $1 \mathrm{~d}$ and 2) whose activities make the machine (which has become the ground upon which the story unfolds) run.
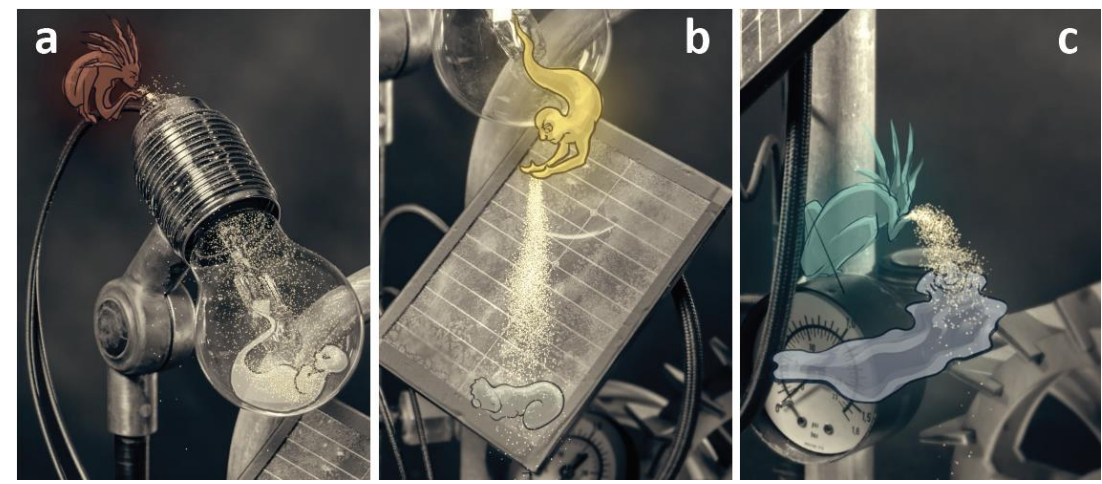

Figure 2. Forces of Nature are represented as little spirits that take roles of agent and patient when they interact in a device: bulb (a), solar cell (b), or pump (c). In the interaction, the tense agent "hands" dust (representing energy) to the relaxed patient. The agent relaxes, and the patient tenses up. (Stills are taken from Deichmann's animation [35]).

The activities of the spirits consist of movement from one location to another and interactions with other spirits. The interaction of two spirits-when one is the agent and the other the patient-happens in what, from a material standpoint, are devices from which the machine is built. These devices, such as lamp, solar cell, and pump (Figure 2), become "meeting places" for the Forces of Nature in their interactions.

When two agents, i.e., representants of Forces of Nature, "meet," we see how chains of processes are created. An agent has brought energy in the form of dust which it now exchanges with the patient. The agent is tensed, whereas the patient is relaxed. Upon the exchange of dust (energy), they change their states: the agent relaxes and becomes a patient for further (later) action; the patient tenses up and becomes an agent who carries the dust (energy) to the next "meeting place". 
Naturally, the exchange of energy in an interaction can never be ideal: some of the dust (energy) will inevitably fall to the ground, where it will be picked up by a new agent that is created in this act: heat. This explains irreversibility (the production of entropy) and creates the ground for an allegory where the machine operates as an open flow system in analogy to the surface of our planet bathed in the light of the Sun.

\subsection{Energy in Science and Teaching}

The foregoing remarks concerning how we will treat the concept of energy in our proposals for FoN-T performances might strike physics teachers and researchers in Physics Education Research (PER) as too untraditional, and therefore requiring justification. Even though, with this paper, we do not wish to add to PER in general, and to discussions relevant to the teaching of energy in typical physics courses that make a claim to contribute to physics as a field of formal science, we should briefly discuss the energy issue from this more formal perspective at this point.

As we have stressed above, the scientific bases of our approach can be found in the most general theories of macroscopic physical processes; see [8] and the relevant literature on continuum physics [5-7,9]. Since these theories present us with a generalized approach to processes and the role of energy in these processes, there will necessarily be "untraditional" aspects to our treatment. As formally presented, however, our approach to energy is foundational, particularly in the applied sciences and engineering [48,49]. Let us see how work done in PER stacks up against this foundation.

The reason for the "untraditional" aspects is simple: the generalized approach to macroscopic physical systems and processes created in continuum physics is unknown in typical physics courses. Starting in the early 20th century, research physicists turned their attention to what is often called "modern physics" (relativity and quantum physics). Continuum physics, as a generalized approach, is a modern invention as well; its development started around the middle of the 20th century [5], largely initiated and continued by mathematicians and engineers who modernized the tradition of continuum mechanics. Continuum physics is applied today in large-scale computational models in astrophysics, geophysics, the physics of the atmosphere and the oceans, and engineering (such as fluid mechanics and continuum thermodynamics in aeronautics). Today, it is behind a good part of the modeling that goes into climate science. We might say that traditional (school) physics courses are children of "modern physics", whereas our approach is a child of modern continuum physics.

First, taking a PER perspective, we should note that there simply is no agreement to be found among PE researchers how to teach the energy principle [50]. There are very interesting proposals based upon PER that deserve our attention if we wish to teach a physics course (at levels ranging from middle school to introductory and advanced university in courses for scientists and engineers; see [51-54]). Interestingly, the newer literature in this field increasingly treats the energy concept from a perspective inspired by embodied cognitive science (see, in particular, $[43,55])$.

Importantly, we are not aware of any attempts, in all these proposals, at covering the generality and extension of the energy principle, as put forward by continuum physics in models of macroscopic systems and processes (for what this generality entails, see [8], and the literature on more formal approaches to continuum physics: [5-7,9]). Maybe, the most important "nontraditional" element is the role of energy in the interaction of Forces of Nature where energy is made available and used, or, in imaginative parlance, where it is handed from one Force to another. Our notion of "making energy available" is a generalization of the concept of available power and availability that was introduced in modern thermodynamics more than half a century ago [56-58]. Put formally, our approach to energy exchange in the interaction of FoN where energy is made available and used is a generalization of what, in continuum mechanics, is called stress power [6] (p. 228), [8] (p. 469). In the simplest case of a single dimensional medium admitting a conductive transport of energy in mechanical processes, the divergence of the energy current density can be split into two 
terms: $\mathrm{djE} / \mathrm{dx}=\mathrm{v} \cdot \mathrm{djp} / \mathrm{dx}+\mathrm{jp} \cdot \mathrm{dv} / \mathrm{dx}(\mathrm{jE}$ is the energy current density, jp is the momentum current density, i.e., stress, and $v$ is the speed of the point where the energy current density is measured). The second term on the right-hand side is the stress power. If integrated over the volume, we get a quantity which is a special case of our generalized notion of power, which can be represented visually in process diagrams (see Section 4.1). If PE researchers were so inclined, they could take the imaginative approach to an extended energy principle laid out in our paper (as an element of FoN-T pedagogy) as a modest proposal for the more serious and formal work needed on this subject in scientific approaches to energy in physics courses.

Second, with research on conceptual metaphor and embodied cognition in science learning, new aspects regarding learning about energy have emerged [43]. Even though energy is an abstract concept, its main conceptualization, both in scientists' and in students figurative language, is that of a substance [52,53,59-61], so much so, that Lancor [60] p. 1260 , after analyzing textbooks and the science education literature, concludes that "... the vast majority of discourse about energy implies that it is a substance. Although widely accepted that energy is not actually a substance, it is virtually impossible to discuss energy without referring to it as a tangible quantity." To partly answer the initial question of how PER is relevant for treating the energy principle in our approach in general and in FoN-T performances in particular, some valuable contributions come from work in embodied cognition and figurative thought [2-4,43,55,59-61].

Third, there is little to be found in the PER literature referring to teaching the energy principle in primary school that does not derive from traditional approaches to school physics (see $[62,63])$; the one notable exception to this state of affairs is the approach to the energy concept developed in the Karlsruhe Physics Course where a textbook on energy was produced for children [64]; there, the notion of energy carriers was introduced. Energy carriers are one of the elements of our FoN-T performances (see our Section 4.2). To be clear, by "school physics", we mean the typical courses that are simplified but still formal versions of what is considered fundamental in physics by modern researchers in the field: relativity, quantum physics, and modern materials science. Teachers accept the primacy of motion for all other phenomena (this, by the way, precludes the analogical treatment of the different basic physical phenomena such as fluids, electricity, heat, motion, and chemical processes; analogical reasoning cannot be applied to members in a hierarchical structure) and, even if they talk about macroscopic systems in fluids, electricity, and heat, they will always have microscopic models in mind. However, there is an entire world out there- the world of our primary experience - that is neither exceedingly small, nor moving exceedingly fast, nor subjected to exceedingly strong gravitational fields; to this world, we direct our attention.

Finally, and most importantly, in this paper, we do not take a formal scientific approach to the energy principle. With regard to energy, we are attempting to deal with the question of how the experience of "power" and "agency" made by every human directly encountering FoN in nature, in our bodies, or in machines can grow-through embodied simulations of the FoN-T type-into a qualitative notion of energy which, in later formal educational settings, can be translated into a generalized and extended energy principle.

\section{Embodied Simulations-The Dynamics of a Single Force of Nature}

Since (1) formal scientific representations are both metaphorical and narrative, and (2) metaphor and narrative spring from embodied experience and feed back to our embodied mind, it should be possible to use our bodies as tools for simulating — and so learning to understand-physical systems and processes. Here, we begin by discussing an example of the activities of a single FoN in a simple system, by creating a short sequence of ES. Interactions of different Forces of Nature that introduce us to the role of energy will be described in Section 4, where we discuss examples of FoN-T performances. First, however, we describe, in more detail, some aspects of the scientific background of our understanding of FoN. 


\subsection{Scientific Background: Tensions, Storage, and Flow}

Since we use our everyday physical experience with actual fluids in our schematizing and metaphoric transfers and conceptualizations of the various fields of macroscopic physics (remember the concept of fluidlike quantity, see Section 2), let us discuss an example from storage and flow of fluids and allude to other processes where appropriate. Consider the simple case of a single tank: we let water flow in at the top at a prescribed rate, and the water can flow out again through a horizontal pipe at the bottom of the tank (Figure 3).
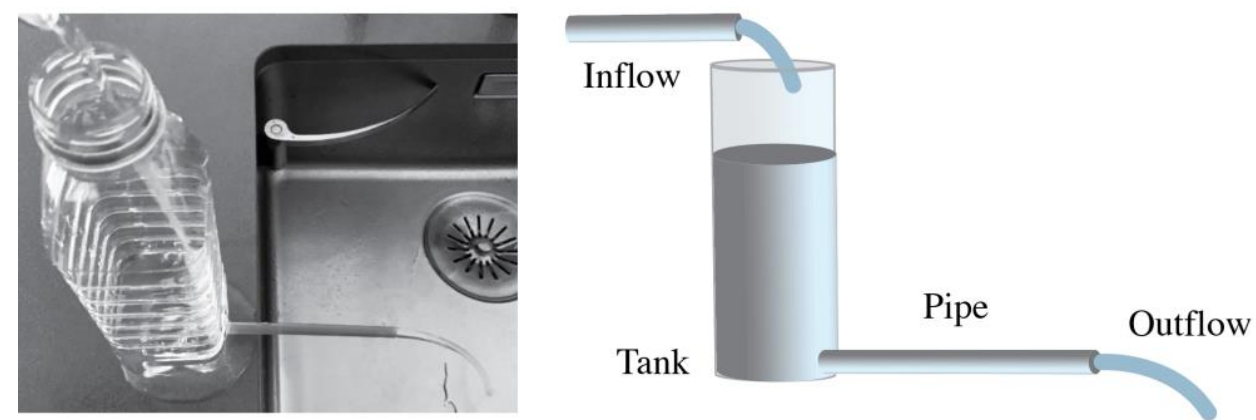

Figure 3. A container is filled with water and drained at the same time. In this example, the only FoN of interest is water (described in terms of volume, flows, and pressure differences).

\subsubsection{Dynamical Model}

This example allows us to study at least three aspects of interest: (1) balance of amount of fluid, (2) relation between amount of water stored in the tank and hydraulic tension (pressure difference across the column of fluid), and (3) relation between outflow and hydraulic tension (pressure difference along the water in the pipe). A map of how these relations fit together is shown in Figure 4. Actually, there is a fourth relation of fundamental importance: the relation between pressure differences (tensions) along a (closed) path through a system (i.e., Kirchhoff's Second relation in electric circuits applied to hydraulics). We shall not consider this here for the sake of brevity. Often, the tensions at work are clear from the circumstances described.

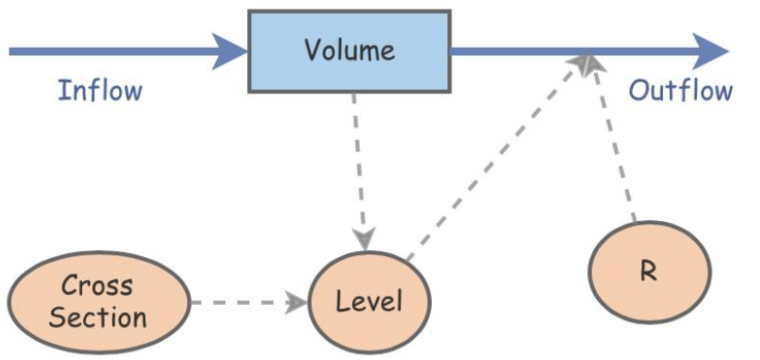
(a) $d / d t$ (Volume) $=$ Inflow - Outflow
(b) Init_Volume $=40$
(c) Inflow $=4$
(d) Outflow $=$ Level / R
(e) Level $=$ Volume $/$ Cross_Section
(f) Cross_Section $=2$
(g) $\mathrm{R}=2$

Figure 4. Left: Graphical representation of ideas making up a model of draining of a tank through a horizontal pipe at the bottom. Right: Equations making up such a model. The example in this figure was constructed in InsightMaker (insightmaker.com; accessed on 8 November 2021). Note that the equations are written using the names of variables in the model diagram. (Reprinted from [12]).

The balance of volume of water of the single tank takes the form

$$
d V / d t=I_{V, \text { in }}-I_{V, \text { out }}
$$

The relation between amount (volume $V$ ) of water stored and hydraulic tension (pressure difference $\Delta p$ across the column of water) is given by

$$
V=C_{V} \cdot \Delta p
$$


Finally, if the outflow is laminar, it is related as follows to the hydraulic tension of the water in the pipe:

$$
I_{V, \text { out }}=1 / R \cdot \Delta p
$$

The inflow will be fixed explicitly. Note that the hydraulic tensions across the column of water in the tank and the water in the pipe are equal. Here, $C_{V}$ is the hydraulic capacitance of the storage element, and $R$ refers to the hydraulic resistance (in the case of laminar flow).

If we add an initial value of volume of water $(V(0)=V 0)$ to the three equations of the model, we have a complete mathematical form of a dynamical model, whose simulation will tell us how the water will behave in this system. There exists software with graphical user interfaces making use of visual forms of basic schemas and metaphors that allow us to create and simulate such dynamical models [65]. The graphical representation of the model presented here is shown in Figure 4.

The basic concepts and the relations between them presented in our example repeat in analogous fashion across (most of) the different fields of macroscopic physics. Importantly, concepts and relations admit imaginative representations that can be rendered as physical simulations (both in embodied play and in board games; see Sections 3.2 and 3.3).

To be concrete, the situation represented in our example is analogous to the filling and discharging of our aorta, an electric capacitor being charged and discharged at the same time across a parallel resistor, water being heated in a pot on a stove, or a body falling in air. The only difference of the case of the aorta to the model in Figure 4 is found in the particular form of the inflow (which is governed by the hydraulic tension of the blood between the left ventricle and the aorta). In the case of the capacitor, if it is charged with the help of a battery across a resistor, the inflow of charge is again determined by circumstances. The thermal and the mechanical examples, on the other hand, might be quite literally analogous to the model in Figure 4. These analogies will allow us to represent the different cases pretty much in one and the same type of ES. All that changes are the names of some of the quantities we are dealing with.

\subsubsection{Filling and Discharging the Aorta}

To make the example a little more interesting and closer to our own bodies, let us turn to the simplest possible model of the systemic blood flow system. This is the part of the circulatory system of mammals that includes the left ventricle of the heart (plus valves), the aorta, and the blood vessels that transport blood from the aorta through the body back to the right ventricle. To make it as simple as possible, we limit our attention to the filling and discharging of the aorta (Figure 5). The aorta is the vessel we are interested in, in analogy to the tank in Figure 3. Blood is forced into the aorta from the left ventricle and flows out again through arteries, capillaries, and veins; together, the vessels work like the drainage pipe in Figure 3. The only relevant difference between this simple model of the systemic circuit and the example of tank and pipe is the form of the inflow: in the case of our circulatory system, the inflow is highly pulsed (rather than being simply constant). The model presented here is called a windkessel model-in analogy to the hydraulic system (consisting of an intermittently working pump, a pressure vessel, and a hose) invented in the 17th century for the purpose of firefighting ([8] Chapter 1).

The physical situation of filling and simultaneously draining the aorta lets us experience a phenomenon that can be analyzed into a small number of constitutive aspects. Filling the aorta with blood makes it expand; as a result, as the volume of blood increases, the tension (i.e., the pressure) of the blood will rise (just as the water level in the tank in Figure 3 will rise). Put yourself in the place of the blood in the aorta: it will "feel" its tension rise as it gets more and more "crowded" in the aorta. The formulation chosen here (" ... it will feel its tension rise ... ") shows that we have performed a Figure-Ground Reversal (see Section 4.2) and have made blood a character whose actions and experience explain the phenomena under investigation. Note that the rise of pressure is caused by the rise of 
mechanical stress of the vessel (the wall of the aorta) rather than by gravity, as in the case of an open tank being filled with a fluid.

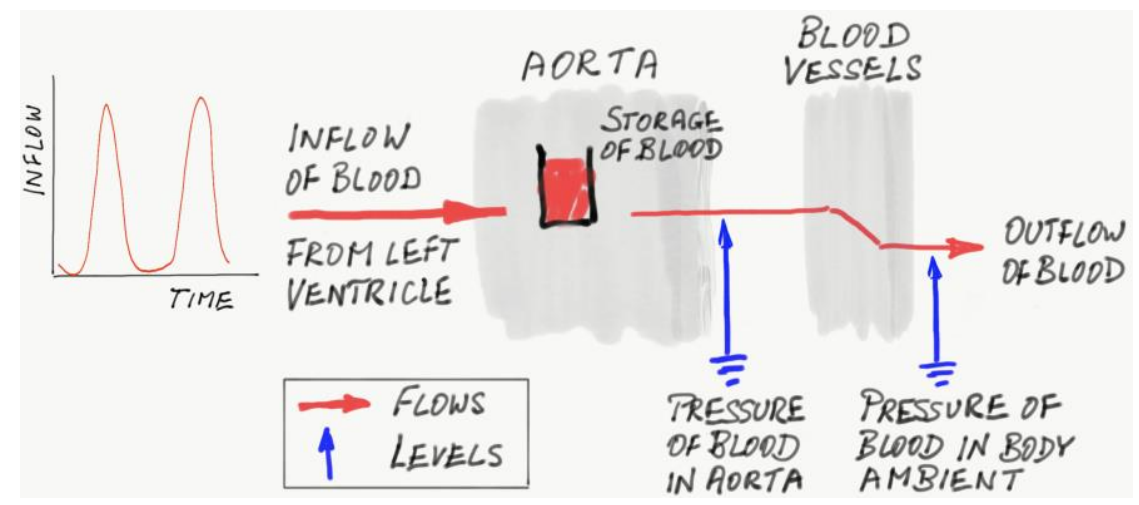

Figure 5. A diagram depicting the role of (amount of) blood in simultaneous filling and draining of blood from a tank (aorta). Flows are depicted by (red) lines and arrows; pressure is symbolized at a metaphoric level. The flow of blood into the aorta (driven by the left ventricle) is highly pulsed. Note the absence of energy quantities in this model—they are not needed.

Second, there is the phenomenon of flow out of the aorta resulting from tension, i.e., the flow of blood from the aorta where the pressure is high to the ambient in our body where the pressure will be low (note the element called Blood Vessels on the right in Figure 5). Blood "crowded" into the aorta "feels the urge" to get out into the body where the pressure is lower. Third, there is the issue of what is going on with amounts of blood in the aorta; this raises the question of how we can keep track of such amounts in a dynamical situation, resulting from storage and flows.

All three aspects (volume-tension relation, tension-flow relation, accounting for amounts of blood) can be simulated and so experienced in a manner that allows for our body to become a partner in cognition. For the third of these aspects, we can also easily create a board game that can teach us how to perform accounting for amounts of a fluidlike quantity.

What is missing from this list is the role of energy in the description of processes; it turns out that the concept is not needed for understanding this type of simple situation. This is standard in the physics of dynamical systems if a single FoN is involved-in macroscopic physics, models are created without the need for energy relations. While this is typical of mechanical models that are formulated based upon the balance of momentum (where energy is at best an auxiliary quantity, an "integral of motion"), the same holds for hydraulics, electricity, thermodynamics, and chemical processes as well [8]. Further below in Section 4, we shall suggest FoN-T performances that allow us to play the "energy game" superimposed upon what the agents representing Forces of Nature are doing.

\subsection{Designing Embodied Simulations}

We now use the example of the dynamics of blood in the aorta and turn the three aspects mentioned into ESs.

\subsubsection{Simulating Fluid Tension}

Imagine "packing" a fluid into a container; better still, imagine that you are blood, i.e., put yourself in the place of blood in the aorta and ask yourself what you will feel. Cristina Mariani called questions of this type "embodied questions." See [66,67]. These "embodied questions" call upon a form of imagining that has been described as imagining-how: "This kind of imaginative activity is not realized by projecting an unfolding scene of which the imaginer is the mere witness, but rather by entertaining an imagined state of affairs in which he [... ] is envisaged as himself an active and embodied participant." [68] (p. 45). All we need for an ES of blood pressure is a fairly large number of people, a large enough 
space for a stage, and maybe a rope for designating a part of the floor as the inside of the aorta (Figure 6).

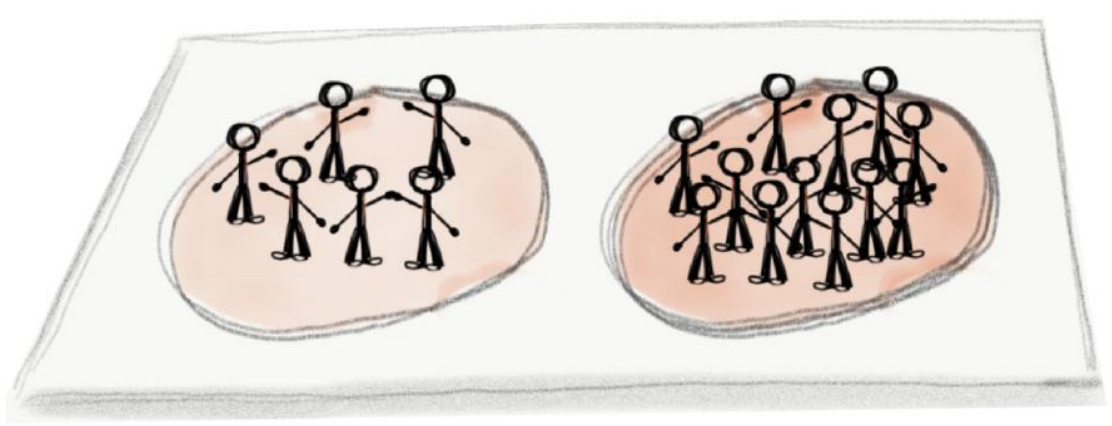

Figure 6. Fluid tension can be made felt. We designate an area on the floor as the inside of a fluid container. Persons crowd into this area, and the degree of crowding gives a feeling of the embodied meaning of pressure.

Clearly, if we accept the image of quantity of blood as fluidlike, packing more and more of it into a certain storage element will let its tension rise. If people represent blood, we obviously need to model the increasing amount by an increasing number of people inside an area on the floor, designated as the inside of the aorta (see Figure 6). If everyone stretches out their arms and touches someone else, the denser we are packed, the stronger the pressure or (mechanical) stress felt in our arms as we have less and less space to ourselves will be. We feel tensed, and the higher the number of people, the higher the tension will be.

In a slightly more realistic simulation, we could designate a number of actors playing the role of the wall of the aorta. In place of the rope separating the aorta from the rest of the world, the actors can form a tight circle, holding hands, around the people symbolizing blood inside the aorta. We let more "blood-people" enter the circle which makes the inside more crowded and forces the circle to be stretched. Whereas the people simulating blood will be under compressive stress, the actors in the circle will feel tensile stress.

In the analog case of heating of a body of water in an open pot over a fire, we need to simulate the temperature as the tension felt by people crowded into a space representing the water (the actors represent heat-as-substance, i.e., entropy). It is like the case of pressure of a fluid: entropy is "under pressure," and it will eventually find its way out of the water, however slowly. The tension felt by the actors "crowding into the body of water" is an embodiment of temperature. Note that this situation is very different from the microscopic interpretation of temperature as somehow resulting from the "trembling" or "shaking" of "molecules." In an ES as described here, persons are not molecules, and they neither shake nor tremble, nor race around randomly. All persons together performing the ES are an extensive fluidlike quantity (i.e., entropy), and the tension of this thermal fluid represents temperature.

\subsubsection{Simulating the Flow of Blood Resulting from Hydraulic Tension}

Since there is a pressure difference (a hydraulic tension) between the blood in the aorta and further away in the vessels in the body, blood will escape the aorta and flow into the body. Figuratively speaking, it will be flowing downhill, down a pressure gradient (see Figure 7, left). We can imagine blood to be at steadily lower pressure the farther we go from the aorta towards the ambient.

Here, blood will be represented by a row of actors (Figure 7, right) with arms outstretched and touching the shoulders of the person in front; the stress felt in the arms is supposed to illustrate the level of pressure. Fully representing what we imagine blood is doing and undergoing ("feeling") will not be easy; depicting an active flow requires the actors to easily slide across the floor as they are being pushed. However, a brief moment of the dynamical situation can be represented fairly easily. A first actor (A) symbolizes 
blood at high pressure in the aorta, and actors $1,2, \ldots$ personify blood flowing through the vessels between the aorta and the ambient. If A pushes actor 1 as hard as possible, the intensity of stress felt in the arms by actors $1,2, \ldots$ will go down along the chain-the outermost person representing blood just about to enter the ambient will not need to stress his or her arms. What we can learn from this exercise, apart from the drop of tension/pressure along the row, is that the flow of blood should be stronger if A pushes harder, and weaker if sliding across the floor is harder (this would be analogous to Ohm's rule for electric conductors).
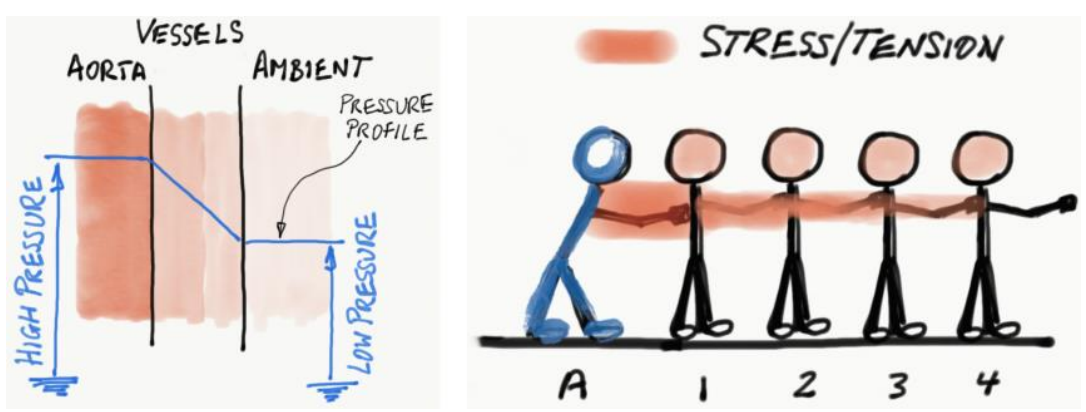

Figure 7. Left: Blood in the aorta is separated from the low-pressure environment (ambient) by the paths created by the vessels. The pressure drops from the aorta to the ambient. Blood will flow "downhill" from the aorta to the ambient (just before entering the right ventricle of the heart). Right: A person (A) pushes hard, simulating the high pressure of the blood in the aorta. A number of persons representing blood can be pushed across the floor. Going from left to right, persons $1,2, \ldots$ feel decreasing stress in their arms as they slide.

The transport of blood through vessels—caused by a pressure gradient-is an example of a type of processes that is fundamental for understanding many physical processes in nature. Therefore, an embodied exercise like the one described here should allow participants to create embodied mental images of how it is for a fluidlike quantity to flow through a medium, caused by the tension associated with the quantity (see Table 1). In science, the class of transport processes where a fluidlike quantity flows because of the tension associated with it, is called conduction or diffusion. They arise in thermal, electric, chemical, and mechanical situations as well as in hydraulic ones. A conductive transport is characterized by the potential difference associated with an extensive quantity (see Table 1 ) being the driving force of the flow.

\subsubsection{Simulating the Process of Keeping Track of Amounts of Blood}

Blood, like any other fluid, comes in amounts, and amounts in a storage element can be counted as they change because of inflow and outflow. In the case of entropy in irreversible processes, and amount of substance in chemical reactions, we need to include the possibility of production/destruction of the amount accounted for.

Again, we can support our imagination by using our bodies for simulating what it means to account for-or balance, as in a balance sheet-quantity of blood or amount of any other fluidlike quantity (see Figure 8). Since we are interested only in the amount of blood and not in its associated tension, all we need to learn is to count such amounts in a situation that evolves dynamically. We will be interested in how this amount changes driven by inflow and outflow (and, if applicable, by production).

We can create an accounting game similar to the one visualized in Figure 8. Learning how to keep track, over the course of time, of the number of people (who, by their number, represent the amount of a fluidlike quantity) in an area designated as a storage element (the area inside the oval in Figure 8) can be done fairly simply.

Assume we have a few children inside the "storage element" on the floor; we need a person who counts their number and reports the result to the record keeper who enters the number in the balance sheet in the column labeled Content. We also need someone who 
keeps track of time; time can be reported in intervals, one after another, each one just long enough for the following to happen. During a time interval, a certain number of children will enter and a (generally different) number will leave the designated area. These two numbers could be predetermined, and they could be equal or different. At any rate, they must be known to the record keeper, who enters them in columns labeled In and Out.

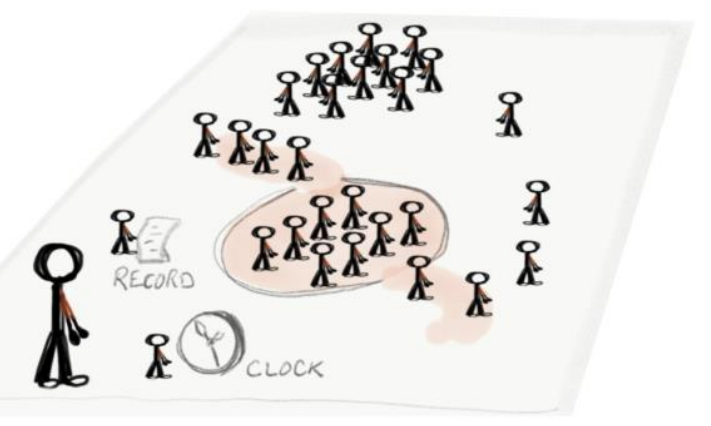

Figure 8. Performing how to keep track of amounts of blood (or any other fluidlike quantity). A designated area serves as a storage element (aorta) for the particular amount. The amount of fluidlike quantity is represented by the number of children. Children can move into and out of the storage area, representing flows of different strengths (symbolized by the rate at which children enter or exit the storage area).

Next, two things are done in parallel, still during the current time interval: (1) the record keeper calculates-updates-the number of children that should be in the storage area at the end of the time interval, based upon influx and outflow and the previous number of children in the oval; and (2) the person counting the number of children in the oval does a new count. Then, the two results are compared-naturally, if all went well, they should agree! If they do, the game continues through the next time interval, and so on. At the end, the balance sheet can be studied. If desired, and if educationally appropriate, the results of the sheet can be graphed, and so analyzed and studied in an alternative medium.

\subsection{A Dynamical System as a Board Game}

What we just described as ESs can be turned into board games. While these are not strictly ES games, they reflect much of what we do when we use our bodies as agents.

\subsubsection{Bookkeeping as a Board Game}

This bookkeeping simulation can be easily converted into a board game. A board with a storage area and paths for inflows and outflows drawn on it, and maybe a bag full of small stones or similar more or less indestructible "pieces" for moving around is all we need.

Let us briefly turn to an example where the quantity in question can flow into and out of the storage element (with one flow going in and one going out) and can be produced simultaneously (this would be the case if we considered a thermal process, or a biological one with births occurring). Pieces that are supposed to flow into the designated storage area on the board come from a particular container set aside for this purpose; pieces flowing out go into another container; and pieces representing production of the fluidlike stuff are taken from a third designated container and dropped directly onto the board into the storage area. Note that we want to move the pieces representing flows from or to their respective containers by moving them along the symbolic paths on the board-this will let us experience a clear difference between stuff that moves in or out across the boundary of the storage element and the stuff that is dropped into it directly from above.

Clearly, it will be easy to model destruction as well-we simply lift pieces out of the element (and then "hide" them in a container marked "destroyed"), and so remove them directly without having them flow across the board. In mathematical terms, a flow across 
the surface of a storage element admits a surface density (current density: current per area). Production, on the other hand, admits a volume density (production rate density: production rate per volume); ([8], Chapter 11).

\subsubsection{Combining Bookkeeping with Modeling Flows}

In the descriptions of both ESs and board games representing the task of keeping track of amounts of fluidlike quantities, we suggested fixing flows and production rates beforehand, which allows us to concentrate on bookkeeping proper and not worry about how processes come about. We can now combine elements of games of bookkeeping with modeling flows resulting from tensions. The example of filling and draining the aorta provides for a situation where the outflow is controlled by the pressure difference between aorta and environment. If we wanted to play such a situation, we would need to introduce a measure of pressure of the blood on the basis of the amount of blood stored in it, and then determine the strength of the outflow based upon the related measure of hydraulic tension.

\subsubsection{Tension in a Board Game}

With slightly more sophisticated materials, we can use board games for modeling the tension of a stored fluidlike quantity as well. Imagine we have a large number of small square tiles that can be stacked, and stacks can be placed next to each other on a board that outlines a square or rectangular storage area. Depending on the size of the area, a certain number of tiles can be laid out next to each other in a layer. A second layer can be placed on top, symbolizing rising tension (say, rising pressure or temperature). The size of the area defines how many tiles will be needed for the tension to rise by one unit of tension (which, in formal terms, is the capacitance of the storage device). In all, we can represent simple yet fundamental relations using board games.

\subsubsection{Advantages and Disadvantages}

There are several advantages to converting the ES into a board game. For one, it can be played by a large number of small groups simultaneously. Second, we can use a large number of "pieces" representing a fluidlike quantity, easily much larger than the number of children available in a classroom ready to perform an ES (this leads to a less discrete and more continuous representation of processes). Third, it is much easier to include processes of production and destruction in such a game. Finally, a board game lets every player get an overview of pretty much all aspects of the processes, rather than having to limit one's attention to a particular role played in the ES. There is a downside as well: we do not get the same direct physical embodied feeling for what is happening to blood (and other fluidlike quantities) as processes proceed.

\section{Forces-of-Nature Theater-The Interaction of Several Forces}

We now turn to a discussion of additional aspects of physical systems and processes (interacting Forces of Nature and the role of energy in such systems and processes). As in the previous section, we shall first consider formal scientific elements (Section 4.1) and then describe how FoN-T performances can be created (Section 4.2). We will then briefly turn to the question of whether or not FoN-T pedagogy, in particular, is amenable to (co-)construction of knowledge (Section 4.3).

\subsection{The Physics of Forces Interacting}

In chains of processes-where FoN interact-a new element appears in our description: exchange, transfer, and storage of energy. Consider an explanation of what is going on if water is pumped with the help of an electric water pump. In order to simplify the situation, we limit our discussion to the case of a steady-state process. We want to disregard specific material aspects, but consider the pump consisting of an electric motor driving a mechanical water pump (Figure 9). 


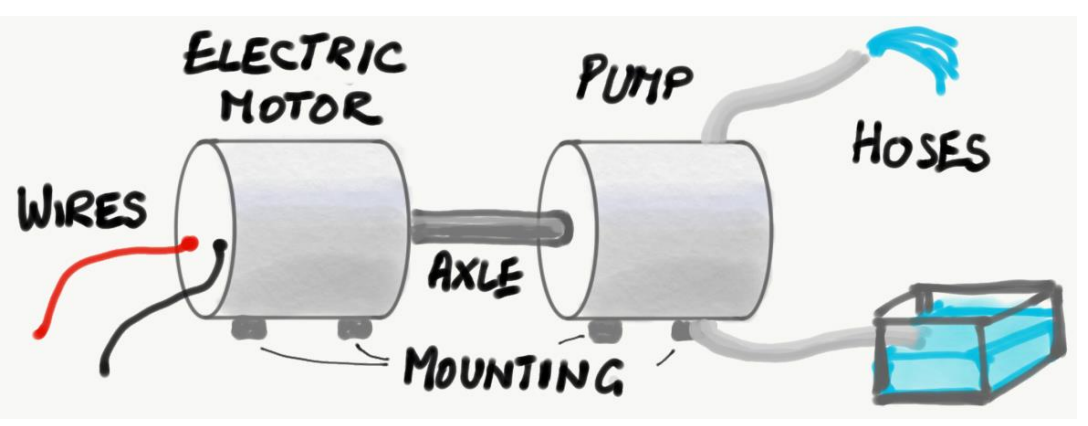

Figure 9. Semi-realistic sketch of a system composed of an electric motor and a mechanical water pump. The system includes wires and pipes or hoses and, depending upon considerations, a generator or battery and storage elements for water.

A bird's-eye view of processes active in the system is achieved if we imagine four Forces of Nature interacting, partly in series, partly in parallel: electricity drives rotation (and produces heat), and rotation drives the flow of water (and produces heat). These Forces act in and through material elements: the electric motor and the pump (augmented by wires, and axel, and pipes; see Figure 9). Note that, even before we have given a more detailed explanation, one thing must have become clear: in our mind, the Forces have taken on the form of figures appearing before and acting upon a ground that is made up of the material elements of the system; we often start by "seeing" the material elements of a system as figures before a ground that is made up of the environment in which we place the (material) system. Forces of Nature appear to us through Figure-Ground Reversal-a cognitive process which is fundamental to human experience [46]. Visual examples of Figure-Ground Reversal are known in art (such as in M. C. Escher's sketches), and simple ambiguous figures (picture puzzles) such as the famous duck-rabbit or reversible goblet pictures. This will be important when we create a schematic representation of the system, processes, and Forces.

\section{Processes Interacting: Process Diagrams}

The explanation of what is going on takes the form of a narrative that can be represented visually as a process diagram (Figure 10; see [8], for background and examples). We start with electric charge flowing through a first wire into the electric motor (in the process diagram, the flows of charge, spin, fluid volume, and entropy are represented by thin red lines and arrows; the mathematical symbol of the various flows is $I_{X}$ where $X$ represents the appropriate extensive quantity, i.e., either charge, spin, volume of water, or entropy). Charge enters the motor at a high level (high electric potential); as it flows through the motor, it drops to a lower level, and leaves the device through a second wire (the vertical blue arrows in Figure 10 are the visual metaphors of potentials). Upon entry, charge carries a lot of energy, which it makes available to the following processes (in Figure 10, exchange of energy - making energy available and using it-is metaphorized by vertical green arrows whereas flow of energy is represented by their horizontal counterparts).

The following processes, the ones driven by electricity, are the pumping of spin and the production of entropy. Pumping and flow of spin are "felt" by the material parts of the system as mechanical stress such as torsion stress in the axle. The potential of spin is rotational speed. Production of entropy is felt by the warming of the materials; temperature is the thermal potential. The energy made available by electricity is split between the two follow-up processes; how the energy is divided up defines the efficiency of the interaction of electricity and rotation.

Spin is pumped from low potential (zero angular speed of the ground and the casings of the devices) to high potential (angular speed of the axle) and then flows through the axle into the mechanical water pump. There, it falls back to the low potential and makes the energy it picked up in the motor and carried to the pump available for follow up-processes. Finally, the spin will flow back to the motor through the floor and mountings. 


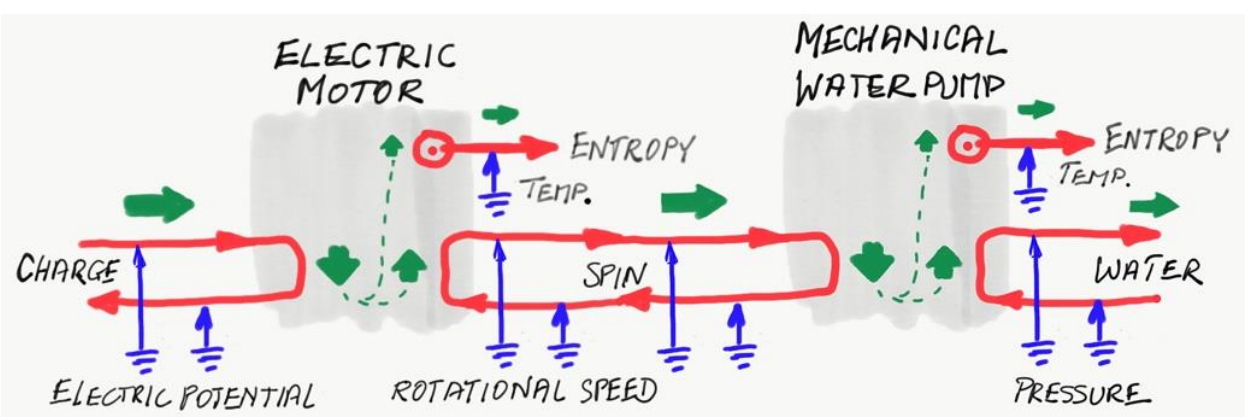

Figure 10. A process diagram of the system in Figure 9 depicts the devices (electric motor and mechanical pump) as ground (gray rectangles) upon which forces are active: charge, spin, water, and entropy flow, and entropy is produced. Their activities are subject to potentials (electric, rotational, pressure, and temperature). The Forces carry and exchange energy.

Rotation, water, and heat interact in the mechanical water pump. The energy made available by spin falling from high to low potential is divided up and used by the hydraulic and thermal processes. Water is pumped from a point of low to a point of high pressure and made to flow through the pump. Again, entropy is produced, and carries away some of the energy made available by the rotational process.

\subsection{Designing Forces-of-Nature Theater Performances}

We shall suggest now how we can use a stage (a large enough empty area on a floor), some material props, and our bodies to create theatrical performances of FoN interacting. This will be particularly valuable in our work with young children. Even though it will be of great importance in concrete educational settings, we shall not discuss the utility of various embodied simulations and plays or games for different age groups. This issue needs to be left to more detailed pedagogical and didactic studies.

The idea for designing what we call FoN-T performances is derived from Deichmann's [35] animated story of a perpetuum mobile. In the animation, Forces of Nature have been visualized as agents at work against the backdrop of physical objects (remember Footnote 26 and the description of Figure-Ground-Reversal). Two simple moves let us create FoN-T performances: (1) we designate areas on the floor as physical devices where the agents meet, and draw connecting lines as paths for the movement of agents (Figure 11), and (2) we let people take the roles of agents and give them confetti or sand to carry as a symbol of energy (see Figure 12); agents, representing different FoN, become energy carriers.

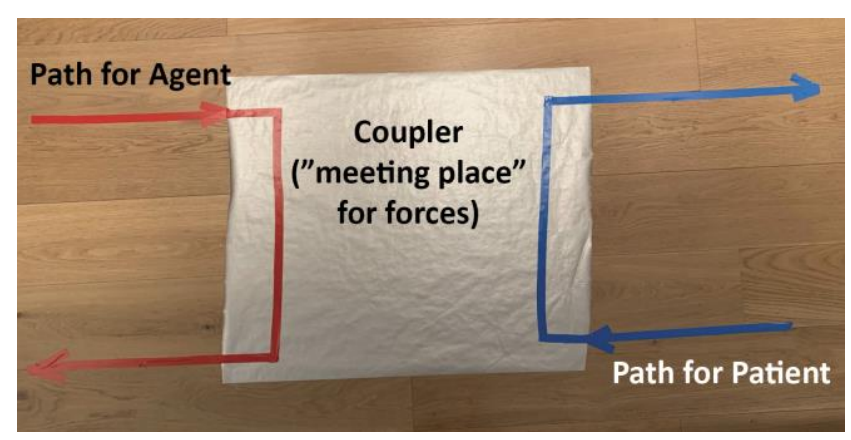

Figure 11. Photograph of the floorplan for a single coupler of a Forces-of-Nature Theater performance. In the simplest case, we have an area marked as a meeting place, plus indications of paths to be followed by agents representing the quasi-material ("embodied") aspect of FoN.

Introducing energy in this manner is a faithful representation-from the viewpoint of modern macroscopic physical theory - of the role of energy in systems and processes [8]; see also $[5,7,9]$. Energy never appears by itself (there is no "pure energy"!); it is always coupled to fluidlike (extensive) physical quantities. A metaphor for this situation is that of 
fluidlike quantities as energy carriers [69]. Our design of FoN-T performances is therefore fundamentally different from Energy Theater [55] (see our brief discussion of the energy principle in science and science education in Section 2.3).
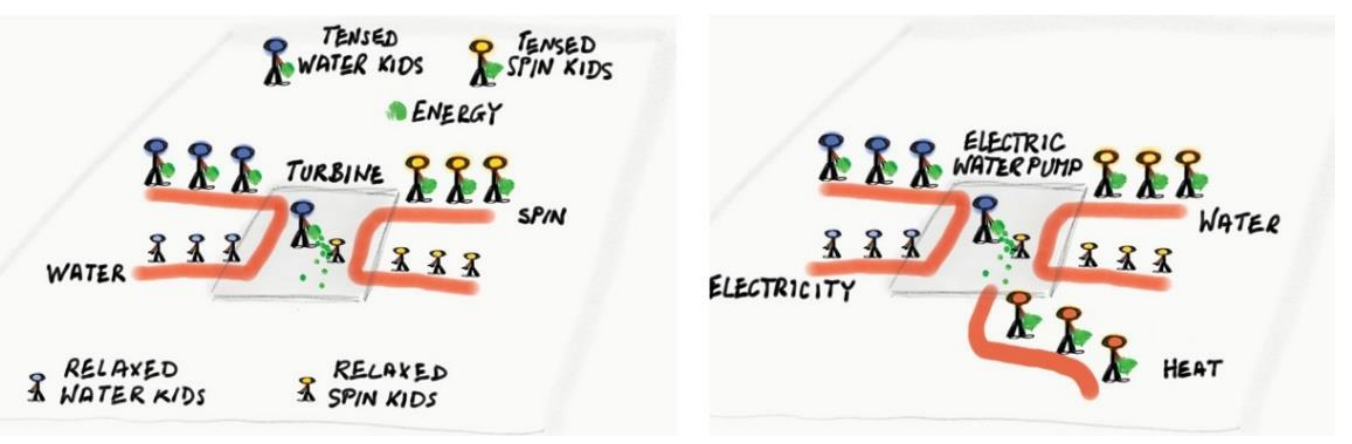

Figure 12. Sketch of the floorplan and actors of a Forces-of-Nature Theater performance representing the operation of an ideal electric water pump (left), and a real pump (including production and emission of heat; right).

We turn the example of the electrical water pump and its processes (discussed in Section 4.1, Figures 9 and 10) into a FoN-T performance. First, we shall take the view of the electric water pump as a single system coupling electricity with water (and heat). After that, we will find out how to create the more sophisticated example of a system composed of two couplers (electric motor connected to mechanical water pump, as in Figure 10).

\subsubsection{Couplers and Paths}

To set the stage, we need to create an abstract representation of parts making up a physical object in which forces act and interact; such parts are devices and their connections. The devices are turned into meeting places called couplers - these are the locations where forces couple or interact (they are the gray rectangles in process diagrams as in Figure 10). Their connections are the paths that make it possible for agents to move from coupler to coupler. Whatever we do, the layout of the stage must map the main features of the topology of the physical system we wish to model-if we consider an electric water pump as a single device where electricity drives water, and if we neglect production of entropy, the layout of the floor might look as in Figure 11.

In general, a coupler will be marked as a simple schematic form on the floor, maybe a rectangle chalked on the ground, or a large blanket laid out. We simply need a bounded space big enough for at least two persons meeting and exchanging confetti (energy); ideally, the space should be bigger, allowing for "processions" of persons marching through as the individuals of two "processions" (agents and patients) interact (see Figure 12). In our example, the space would represent the electric water pump.

The paths taken by the agents need to be marked clearly as well (colored lines on the left and the right in Figure 11). In real life, these paths might be electric cables, water pipes, axels, or any other physical object through which quantities such as electricity, water, amount of heat, or amount of motion (in our case, spin) can flow. (In the case of (sun) light, the path would be made up of the electromagnetic field between source and sink.) If we have two agents such as electricity and water that can be neither produced nor destroyed, and if we assume steady-state operation of the device, all we need are two closed paths along which actors for electricity and water can move into and out of couplers.

The case of electricity (electric charge) is clear: it enters the coupler "from above" (metaphorically speaking, at high level or tension), flows through the device, and leaves at a "lower" point. Water behaves quite analogously to electricity: it enters the pump through the first pipe or hose at low tension (low pressure) and is pumped to a higher metaphorical level (high pressure) and leaves the device. The colored paths taped on the floor in Figure 11 help the "movements" of electricity and water to take the correct form. 


\subsubsection{Agents and Patients, and Their Interactions}

Now that the stage has been prepared, we can move on to instruct the actors in the details of the performance. Remember that we identify Forces of Nature by three fundamental characteristics: extension (quite often as amount of fluidlike quantity), intensity and its differences (tension), and power. The first of these is suggestive of a metaphoric quasimaterial which we now render physical by employing our own bodies; put differently, we use the material aspect of our bodies for representing the extensive aspect of fluidlike quantities-size or amount. Flow or, more precisely, strength of flow, can be rendered as rate at which a "procession" of actors moves along their designated path.

In a FoN-T with children, we should use as many kids as possible that can fit onto our floor designs. Having as many "bodies" as possible will move us closer to how we imagine properties and behavior of fluidlike quantities such as water, heat, electricity, and spin, and constitutes an important step towards a more formal scientific representation of processes. Then, we divide them into two groups: electricity-kids and water-kids. The two groups form moving queues (processions) for electricity and water, respectively (Figure 12). Ideally, this will allow the actors to get a feeling for the strength of the current of a fluidlike quantity, by adjusting the speed at which they move along their assigned paths. Note that the strength of currents of charge, entropy, or momentum is the rate at which these quantities are transported through physical systems-this has nothing to do with physical speed (as in the motion of macroscopic bodies). The speed at which actors move in a FoN-T performance is a metaphor for the strength of the current and, as a consequence, of the rate at which energy is carried from device to device as well.

Naturally, this needs to be practiced with the actors, especially if they are relatively young learners.

The two moving "processions" of actors representing electricity and water, respectively, will meet-possibly in a counter-flow arrangement, as suggested by the floor plan in Figure 11 and in the diagram on the left in Figure 12-in the designated space for the coupler (i.e., the electric water pump) and exchange energy. We shall discuss the role of energy in a FoN-T performance below.

Electric charge and amount of water (volume) are "conserved," a property that is easily modeled if "bodies" do not get lost or "destroyed" along their paths and during interactions. Moreover, if we make it quite clear to participants that they do not "mix," that electricity-kids do not become water-kids and vice-versa, we create the foundations for an all-important insight: the extensive aspects of FoN, i.e., amount of water and electricity, can no longer be confused with energy.

This confusion constitutes one of the enduring misconceptions learners of physical science carry around. Typically, the issue is not expressed explicitly in the teaching of physics. This may very well be for a lack of knowledge of imaginative structures of understanding our encounters with forces of nature. Formalisms do not help learners to overcome this misconception, and neither does our penchant for mechanical explanations of everything happening in nature. If the world is made of two things-matter and energy - everything "invisible" or "immaterial" must surely be energy, and this includes heat, electricity, and motion.

Representing non-conserved quantities such as entropy or light in an embodied performance poses a certain challenge-actors cannot literally be created or destroyed. The director of the enactment of interactions of FoN will have to use her/his imagination and instruct actors in how to interpret production ("being born") and destruction ("dying"), and use props that may help in simulating the processes, so they become "believable." In the sketch on the right in Figure 12, we have included the irreversibility of the interaction of electricity and water in a real pump-it is clear that we need to somehow create a "source" of actors (representing heat-as-substance, i.e., entropy) that can move out of the couplers as they are "created" or "born." In other words, we need a third group of agents, namely heat-kids. Letting them be "born" means that they did not exist before the act. We might 
use a curtain for heat-kids to hide behind before they enter the scene; we will see shortly what else they need to do.

\subsubsection{Tensions}

Tensions are exactly what we feel and imagine them to be-differences of intensities such as brightness, hotness, or speed, which we measure as degrees along a scale. Our bodies convey this feeling, and we can use our bodies in various ways for expressing it. If I am a representant of water at high pressure, I can exhibit this by my posture or through facial expressions-I walk upright, erect, and my face shows high tension or happiness. In Deichmann's animation of the Perpetuum Mobile story, we see this in the expressions displayed by the little spirits.

When I am water, electricity, or entropy at low pressure, electric potential, or temperature, respectively, I can exhibit this by slouching and letting my shoulders droop, and by showing a sad, droopy face.

When an agent meets a patient and they interact, what happens is this: the agent goes from a state of high to a state of low intensity or tension, whereas the patient undergoes the reverse process (in Figure 12, these changing states are expressed in terms of size of individual figures). The agent becomes ready to be a patient, and the patient turns into an agent (so, activities can continue down a line of couplers and processes, see Figure 13). Actors playing Forces in FoN-T performances will be asked to perform exactly these embodiments of states of high or low tension, in order to show what is happening in the physical situation that they enact.

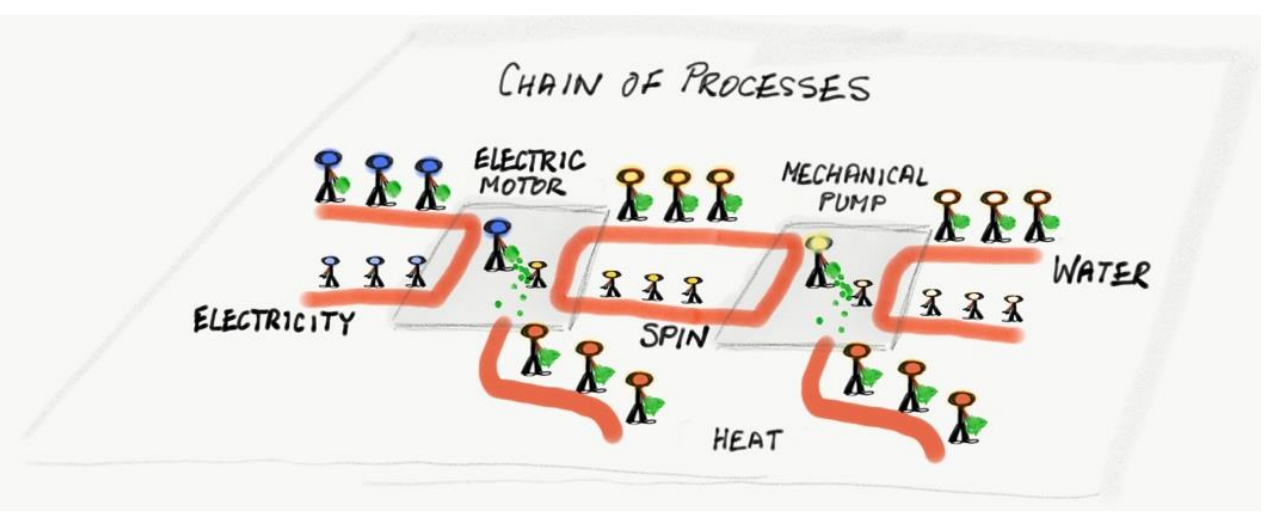

Figure 13. Layout of a FoN-T performance of an electric motor chained to a mechanical water pump. Both devices feature dissipative interactions.

\subsubsection{Energy}

Add energy to all this, and you have created a performance analogous to Deichmann's animated story. In place of the dust in the animation, we can use anything that comes in lots of small pieces that are easily carried in our hands and handed from agent to patient-confetti or (dry) sand will do just fine.

Agents at high tension are "loaded" with energy; they have their hands full with this stuff. In the situation depicted in Figure 12, electricity-actors bring energy with them when they enter the coupler; they hand what they carry to the waiting water-actors, relax, and leave the meeting place. The relaxed water-actors catch some of the confetti or sand, tense up, and move out of the coupler on their way to the next meeting place where the play continues.

Naturally, some confetti or sand, or something else we carry will fall to the floor (Figure 12, right). This is the opportunity for heat-actors to "come into being" as they pick the confetti up that fell to the floor. They tense up and leave the coupler, never to be seen again ... . 


\subsubsection{A Chain of Couplers and Processes}

We can continue this form of performance in a chain of interacting FoN. Our discussion of the electric water pump as consisting of two distinct elements-an electric motor and a mechanical water pump, see Figures 9 and 10—suggests how such chains may be constructed (Figure 13).

The spatial layout requires two connected couplers on the floor: a space for an electric motor and one for a mechanical water pump. Furthermore, we need an additional group of agents: spin-kids. The couplers are connected by a circular path for spin (the physical elements making up this path consist of axle, gears, casings, mountings and ground, and the electromagnetic field in the electric motor). Spin-kids will move around the closed path as a conserved quantity, picking up confetti in the motor, and handing it on to water-kids in the pump.

Note that the representation of systems and processes in the form of a FoN-T performance is a fairly faithful rendering of the corresponding process diagram (Figure 10).

\subsubsection{Summary}

In order to make a FoN-T performance possible, a small number of things are needed. We need a stage, and time-after all, a story is to be told. We need some materials for creating spaces representing couplers and paths connecting them on the floor. We need groups of actors that represent two of the three fundamental aspects of Forces of Nature: extension (bodies) and tension (demeanor); and finally, we need some dust-like stuff (such as confetti or sand) that symbolizes energy as it is carried around and exchanged in interactions (see Table 2).

Table 2. Deichmann's animation [35] and embodied performance compared.

\begin{tabular}{|c|c|c|}
\hline Scientific Elements & Animation & Forces-of-Nature Theater \\
\hline $\begin{array}{l}\text { Physical elements } \\
\text { (devices and connectors) }\end{array}$ & Drawings of physical objects & Spaces and paths on floor \\
\hline $\begin{array}{l}\text { Extensive aspect of force of nature } \\
\text { (amount of fluidlike quantity) ... } \\
\ldots \ldots \text { and its flow }\end{array}$ & $\begin{array}{c}\text { Drawings of "spirits" } \\
\text { Speed at which spirits move through scenes }\end{array}$ & $\begin{array}{l}\text { Bodies of actors } \\
\text { Speed at which columns of actors move } \\
\text { along paths (or rate at which they are } \\
\text { "born" or "killed") }\end{array}$ \\
\hline $\begin{array}{l}\text { Intensive aspect of force of nature ... } \\
\ldots \ldots \text { and its change }\end{array}$ & $\begin{array}{c}\text { Demeanor of spirits (expression of tension) } \\
\text { Tensing and relaxing }\end{array}$ & $\begin{array}{c}\text { Demeanor of actors (expression of tension) } \\
\text { Tensing and relaxing }\end{array}$ \\
\hline Energy and power & Dust and rate of exchange of dust & $\begin{array}{l}\text { Confetti or sand and rate of exchange of } \\
\text { confetti or sand }\end{array}$ \\
\hline Interaction & Meeting of spirits and exchange of dust & $\begin{array}{l}\text { Meeting of actors and exchange of confetti } \\
\text { or sand }\end{array}$ \\
\hline
\end{tabular}

\subsubsection{Experiencing (“Feeling") Embodied Logic}

In all of this, the persons acting as FoN will experience-literally feel-an embodied (physical) logic of what FoN can and cannot do, and what happens to energy (confetti, sand, etc.) and what not. Just to mention a few points: agents need to be tensed (i.e., "charged") in order to carry energy; agents are not "converted" into one another; agents are not energy; energy is always the same as it makes its way through a chain of devices and processes-energy does not change form or the like; energy is "handed" from agent to patient (made available and picked up or used); and there is always the same amount of energy in the system and its surroundings—it is just not available all the time. In order for it to be made available at all, there need to be tensions. (This answers the age-old paradox: if energy is always there, why do we have an "energy problem?" Energy is simply not what it is all about. Speaking from a perspective of nuclear reactions, hydrogen is in an "aggressive" or "tensed" state and so allows our Sun to shine, and we need to wind up the spring of a pocket watch if we want to make it run.) 


\subsection{Transmission or Construction of Knowledge?}

Having arrived at this point, we should briefly discuss the question of whether or not our proposal for FoN-T performances suggests a transmissive didactic model rather than one where (co-)construction of knowledge is favored. (We are grateful to an anonymous reviewer who raised this concern. Naturally, the concern may apply to Embodied Simulations described above as well, but we shall limit our discussion to FoN-T performances.) Before we describe an example of how we would embed single or multiple performances in a longer sequence of didactive activities-that may last for months or even a few years-we would like to draw an analogy with creating and performing a (literary) play in primary school.

Some philosophers have convincingly argued that we learn to understand other people primarily through hearing stories read to us when we are young and by reading novels when we are older (this is the Narrative Practice Hypothesis, see [1,70,71]; see also [45], on narrative experiencing). Imagine now that a teacher and the children of a primary school class put together a play of Little Red Riding Hood. There will be reading (hearing?) of the fairy tale by the children. There will be discussions of its meaning and then discussions about how it could be transformed into a play. Even though the play will need to follow the "script" of the fairy tale, and the teacher will certainly have a say in how to do certain things (maybe she will even be the "director", creating it will involve much activity by the children and performing it will produce acts of (new and different) experience that lead to (co-created) understanding and knowledge.

We would suggest that FoN-T performances are an element in a lengthy process where children learn to understand Forces of Nature, a process similar to learning about other people as suggested by the Narrative Practice Hypothesis. Creating and performing a FoN-T performance, embedded in longer lasting educational activities, may be even more activity oriented than creating a literary play at school, since it presupposes, at minimum, direct physical experience of forces, such as wind, rain, heat and cold, and electricity in technical appliances. Again, a FoN-T performance should be embedded in a number of interlocking activities. Here is a list of what learning about FoN may ask of the students:

- Experiencing the activity (agency) of Forces of Nature directly in nature and in machines.

- Discussing such experience directly with their teacher.

- Hearing and discussing (and maybe even creating) stories of FoN, allowing for narrative experience of FoN as agents.

- Studying a physical element and its activity (or several interacting elements) such as a leaf, an incandescent bulb, or a motor-propeller driven by a solar cell; discussing, with the teacher, the system, its physical parts, its processes and the FoN that make their appearance.

- Designing a FoN-T performance under the guidance of the teacher.

- Discussing and representing, in various communicative acts, the nature of Forces of Nature as experienced in the play.

The points listed here can—and probably should be—repeated with new examples; moreover, the list should not be assumed to suggest a strictly linear sequence of acts. If a FoN-T play is not the first one ever performed by the students, they will become adept at designing more and new FoN-T performances themselves in the course of the months and years when they study Forces of Nature.

\section{Concrete Didactic Experience, General Considerations, and a Research Agenda}

In conclusion, we shall describe-from the vantage point of pedagogical and didactic principles-some expected benefits of learning about Forces of Nature by actively engaging in ES and FoN-T. At the end, we briefly discuss examples of educational research that could and should be performed in order to lay secure foundations for the approach outlined in this paper. First, however, we will briefly focus on the question if ES and FoN-T and the examples of physical systems and processes described in this paper are appropriate and 
desirable elements of teaching in primary school and in teacher training as well-these parts are largely based on our own experience.

\subsection{On the Appropriateness of ES and FoN-T for Primary Education}

As to the question of whether ES and FoN-T performances, and any concrete example (of the type discussed in our paper) would be suitable, and possibly desirable, for primary school, our answer is an emphatic yes. On general grounds, we refer to science standards in general, and to the standards for "Science, Technology, and Society" ("Sachunterricht") in primary school in German-speaking parts of Europe (see [72]). It becomes clear that the topics treated in our course(s) are in line with what is desired for primary education, provided they are embedded in a context (situated learning). As stated explicitly in [72], primary school pupils should be able to perceive changes in nature and trace them back to regularities (this includes the notion of energy as an essential element of natural processes, including its conservation and exchange); they should explore and analyze the technical function of devices and so clarify questions such as "how do wind and water mills, solar plants, or wind generators work?" They should describe processes using examples from everyday life (such as dynamos/generators and motors [72]). We could even include hydrogen energy technology and fuel cells in the list, as we shall see now.

On practical grounds, we can refer to our experience with teaching in primary schools. Here, we shall briefly mention a large-scale research and development activity undertaken over the last three years. Examples of FoN-T performances have been included as a key activity in the FCHgo! European Project (Fuel Cell HydroGen educatiOnal model for schools, Call H2020-JTI-FCH-2018-1 n. 826246; one of the aims of the project was to introduce into schools the culture of fuel cell technology); this project aims at diffusing the culture of hydrogen fuel cell technology in primary and secondary European schools (mostly for 8-18-year-old students). The project, completed in June 2021, offers a didactic toolkit for schools [73] that has been validated after experimentation in about 50 classes of the five countries of the project partners. Part of the project is an award, "World of the future: the best FCH application", that allows all European schools to participate. Groups of students with their teachers have to propose original projects making use of the FCHgo approach. Data of teachers' and students' reactions has been reported in the official deliverables and is being published [74]. With regard to FoN-T performances, stories, and games, we have experimented with children in primary school (such as in Switzerland, in grades $1-4$, and in Italy, in grades 3-8). What we have learned from students' and teachers' reactions has been positive and encouraging. An interesting result that underlines the appropriateness of our ES and FoN-T proposals, is the fact that groups of students and their teachers took part in the FCHgo award producing original ES and FoN-T performances. We are working to publish an analysis of this experience in a follow-up paper.

Children love to act physically, to move and run, take part in sports, and compete, and they do not seem to have any trouble in following instructions by the teachers; but that does not necessarily mean that they have gained any understanding from their activities. For this reason, it is important to have these young students follow up on their activities by reporting on their experience. We are currently evaluating the materials-mostly drawings and simple write-ups-created by the students after these performances.

\subsection{Educating Student Teachers of Primary School Levels}

The concepts of ES and FoN-T performances that have been presented from a theoretical perspective in our paper have been tested in the context of teacher training $[12,13,16,34]$. The authors are developing a natural science course (focusing on physical processes) for future kindergarten and primary school teachers $[12,16]$ that provides for student teachers to be involved in ES or in FoN-T performances. This happens directly during lectures and labs, and may be part of practice periods in school, or as didactic projects for their exams or master theses. The course has been taught at three Italian universities in the last 8 years, and is currently being taught in the two language sections (Italian and German) 
at the Faculty of Education of the Free University of Bolzano (IT) and at the Department of Education and Humanities of the University of Modena and Reggio Emilia. Details of these courses are described in [12], and positive results from experimentations with student teachers are in $[12,34,75,76]$. As far as examples of systems and processes are concerned, our students have experimented with a range of cases typically found in energy engineering where environment and technical systems (hydro-, solar, wind, and hydrogen energy systems including electrolyzers and fuel cells) are coupled-naturally, all of this in "playful" settings where the investigation of small toy-like systems is brought together with writing of stories of Forces of Nature, and the design of ES and FoN-T performances.

The results are encouraging-student teachers are able to design and perform ESs and FoN-T performances in their laboratory sessions. In the final course exam, a majority of students can demonstrate their understanding of physical processes in simple natural or technical systems (such as the one in Figure 9) by sketching proper process diagrams (Figure 10), writing a description of a FoN-T performance paralleling the process diagram, and writing a narrative explanation (using natural language), which parallels both the process diagram and their design of the theater performance. Interestingly, the last of these three tasks is by far the most difficult for the students-writing a logically coherent description using proper natural language without falling into pseudo-tech babble seems almost impossible for some students. We have therefore decided to change the order of the teaching of examples of physical and technical systems and start with FoN-T performances as embodied explanations of the activities of FoN, and then train students in translating the embodied experience into linguistic products. As in the case of experimenting in primary school, we are working to publish an analysis of previous experience gained in a follow-up paper.

\subsection{Some General Didactic Considerations for Primary Education}

Imaginative approaches based upon Forces of Nature reduce the complexity of the science of physics and make physical phenomena and processes more accessible and more easily understandable and transparent. This is not only helpful for children, but also for student teachers and in-service teachers. We know from various studies [77] that (student) teachers at kindergarten and primary school levels often have an aversion to the subject of physics-they perceive it as being complicated and difficult to understand. Their selfconcept with regard to their ability of dealing with this particular science-in contrast to other social and natural sciences-in kindergarten and primary school is low [77-79]. Our approach could be used in teacher education to try to strengthen students' self-concept as they learn about schemas, metaphors, and narrative structures that can be used to explain many different phenomena in fundamentally analogical forms. (We have previously emphasized that our approach is ideal for empowering teachers to become confident narrators of stories of FoN [80].)

For children, the benefits of analogy are similar: they need to learn only a few basic principles that they can apply to various phenomena and that help them understand what they observe. (Such an understanding would be expressed (and measured) in communicative acts taking the forms of utterances, stories, drawings, games and plays, and ESs discussed in this paper. The particular forms of activities encouraged will depend upon the age of the students.) Thus, once learned, it can be picked up again and again to explain and illustrate new phenomena $[81,82]$. ESs and FoN-T performances should therefore not only be carried out once, but should be performed repeatedly for different systems and processes. Children should learn that FoN can be understood as a frequently recurring mechanism in nature.

Repetition is very important for children, in order to learn and internalize things. If the same principle is taken up more often in class, this has two advantages. On the one hand, it helps (weaker) children to remember it better (through repeated thematization), and on the other hand, it enables (stronger) children to learn new phenomena more or less on their own (through transferring structure by analogy). With the help of recurring 
schemas and metaphors, they can build up their own idea of how something might work that they have (newly) observed in their living world-and how that knowledge may be communicated [82].

We expect children to profit from learning in multi-sensory and multi-modal environments. The methodological approach of ESs and FoN-T complements direct physical experience (where students encounter and sensually experience Forces in nature and in technical systems) and the experience afforded by narratives [12,45]. Indeed, a concrete FoN-T performance implements both sensorimotor perception of the properties and interactions of FoN (by involving our body) and a concrete story. What is happening in such a performance simulates events, agents acting in a scene, and tensions for causing these events: these are the ingredients for a prototypical narrative, i.e., a story [83].

In early science education, children should be enabled to describe observed processes and changes in nature using different forms of communication-in the case of ESs and FoN-T performances, they can even learn to act out such processes. There is no requirement that the children build up the underlying physical terminology in the classroom (linguistic communication will continue to be built upon natural language whose figurative elements are the building blocks of formal renderings as well). Early examples of physical experience and embodied realizations of physical processes can gradually be translated into a more formal language as the children progress through school. In this way, the foundations for later (and easier) understanding of physical processes are laid at an early age, as structures have already been practiced in a playful manner.

In ESs and FoN-T performances, children should be able to slip into different roles (agents and patients representing different FoN) and should also be able to view the play from the outside in order to be able to understand the overall process. Otherwise, they may not grasp the overall play by focusing on their own part/role. Board games can therefore be helpful because they make the overall process visible and manageable. A narrator (e.g., a teacher) can enhance the meaningfulness of the process of simulations and board games by linguistic renderings of the embodied representations.

From a didactic point of view [84], it could be helpful to first clarify the characteristics of the individual Forces of Nature by experiencing them holistically directly in nature, in stories, and through ESs; i.e., in a first step, we would be working on understanding intensity and extension, storage and flow, of a single Force. In a second step, one could then let the FoN that have been previously experienced interact with each other, and so move onto FoN-T performances which, importantly, involve the energy principle as well.

\subsection{A Research Agenda}

In this section, we have already described investigations of concrete teaching in primary school and in student teacher education. Detailed evidence of what has transpired from these studies will be published.

We are more concerned, however, with long-term studies and the involvement of "non-traditional" partners for future studies of ES and FoN-T as part of Primary Physical Science Education. There are new aspects of our approach that should be investigated in more depth.

First and foremost, long-term empirical studies should be conducted, comparing students exposed to the type of multi-stage and multi-sensory approach of ES and FoN-T (described in Section 4.3) with students learning about the same subjects, but without the benefit of ES and theater performances. Our previous studies have been limited to relatively short-term interventions. We are expecting important insights, not just for single activities such as ES or FoN-T, but for our narrative-based approach to Primary Physical Science Education $[12,16]$ as well.

In order to win over "non-traditional" partners-partners that are not normally part of science education - to our endeavor, we have made contacts in the performing arts. Moreover, it would be interesting to organize research projects with physical education experts to complement ES and FoN-T activities. It might be interesting to learn how 
physical exercise and games can parallel and complement the physical experience of FoN, the use of stories of FoN, and the ESs and FoN-T performances described in this paper.

Still, much work remains to be done when it comes to developing and evaluating ES and FoN-T activities in primary school. Systematic investigations and evaluation of the methodological feasibility and the learning effect with children of different ages in the classroom need to be performed. To this end, observations and interviews are to be used to investigate how children take up and accept this learning approach and what long-term (learning) effect such embodiments have on children [85].

Author Contributions: All three authors have contributed equally to all parts of the article. All authors have read and agreed to the published version of the manuscript.

Funding: This research was funded by the Free University of Bozen-Bolzano grant number BW2809 Startup Corni.

Institutional Review Board Statement: The study does not involve humans or animals.

Informed Consent Statement: Not applicable.

Data Availability Statement: Not applicable.

Conflicts of Interest: The authors declare no conflict of interest.

\section{References}

1. Gallagher, S.; Hutto, D. Understanding others through Primary Interaction and Narrative Practice. In The Shared Mind: Perspectives on Intersubjectivity; Zlatev, J., Racine, T., Sinha, C., Itkonen, E., Eds.; John Benjamins: Amsterdam, The Netherlands, 2008.

2. Fuchs, H.U. From image schemas to dynamical models in fluids, electricity, heat, and motion. Examples, practical experience, and philosophy. In Proceedings of the 2006 GIREP Conference, Istanbul, Turkey, 1-6 July 2012; University of Amsterdam: Amsterdam, The Netherlands, 2006.

3. Fuchs, H.U. Force Dynamic Gestalt, metafora e pensiero scientifico. In Innovazione Nella Didattica delle Scienze Nella Scuola Primaria: Al Crocevia fra Discipline Scientifiche e Umanistiche; English Version: Force Dynamic Gestalt, Metaphor, and Scientific Thought; Corni, F., Mariani, C., Laurenti, E., Eds.; Artestampa: Modena, Italy, 2011. Available online: www.hansfuchs.org/LITERATURE/ Literature.html (accessed on 8 November 2021).

4. Corni, F. (Ed.) Le Scienze Nella Prima Educazione. Un Approccio Narrativo a un Curricolo Interdisciplinare; Erickson: Trento, Italy, 2013.

5. Truesdell, C.; Noll, W. The Non-Linear Field Theories of Mechanics. In Encyclopedia of Physics; v. III/3; Flügge, S., Ed.; Springer: Berlin, Germany, 1965.

6. Malvern, L.E. Introduction to the Mechanics of a Continuous Medium; Prentice-Hall: Hoboken, NJ, USA, 1969.

7. Müller, I. Thermodynamics; Pitman: Boston, MA, USA, 1985.

8. Fuchs, H.U. The Dynamics of Heat, 2nd ed.; Graduate Texts in Physics; First Edition; Springer: New York, NY, USA, 1996.

9. Jou, D.; Casas-Vazquez, J.; Lebon, G. Extended Irreversible Thermodynamics, 4th ed.; Springer: Berlin, Germany, 2010.

10. Fuchs, H.U. The Narrative Structure of Continuum Thermodynamics. In Proceedings of the ESERA 2013 Conference, Nicosia, Cyprus, 2-7 September 2013; Constantinou, C.P., Papadouris, N., Hadjigeorgiou, A., Eds.; ESERA: Kaunas, Lithuania, 2013.

11. Varela, F.J.; Thompson, E.; Rosch, E. The Embodied Mind; MIT Press: Cambridge, MA, USA, 1991.

12. Corni, F.; Fuchs, H.U. Primary Physical Science for Student Teachers at Kindergarten and Primary School Levels: Part IIImplementation and Evaluation of a Course. Interchange 2021, 52, 203-236. [CrossRef]

13. Corni, F.; Fuchs, H.U.; Dumont, E. Conceptual metaphor in physics education: Roots of analogy, visual metaphors, and a primary physics course for student teachers. J. Phys. Conf. Ser. 2019, 1286, 012059. [CrossRef]

14. Fuchs, H.U. Il significato in natura. In Le Scienze Nella Prima Educazione. Un Approccio Narrativo a un Curricolo Interdisciplinare; English Version: Meaning in Nature-From Schematic to Narrative Structures of Science; Corni, F., Ed.; Erickson: Trento, Italy, 2013.

15. Fuchs, H.U. Costruire e utilizzare storie sulle forze della natura per la comprensione primaria della scienza. In Le Scienze Nella Prima Educazione. Un Approccio Narrativo a un Curricolo Interdisciplinare; English Version: Designing and Using Stories of Forces of Nature for Primary Under-standing in Science; Corni, F., Ed.; Erickson: Trento, Italy, 2013.

16. Corni, F.; Fuchs, H.U. Primary Physical Science for Student Teachers at Kindergarten and Primary School Levels: Part IFoundations of an Imaginative Approach to Physical Science. Interchange 2020, 51, 315-343. [CrossRef]

17. Fuchs, H.U. From Stories to Scientific Models and Back: Narrative framing in modern macroscopic physics. Int. J. Sci. Educ. 2015, 37, 934-957. [CrossRef]

18. Fuchs, H.U.; Dumont, E.; Corni, F. Narrative minds in the construction and use of theories of forces of nature-A model of experience at different scales. In Narrative, Cognition and Science; ELINAS Series; Sinding, M., Heydenreich, A., Mecke, K., Eds.; De Gruyter: Berlin, Germany.

19. Wise, M.N. Science as (historical) narrative. Erkenntnis 2011, 75, 349-376. [CrossRef]

20. Morgan, M.S. Models, stories, and the economic world. J. Econ. Methodol. 2001, 8, 361-384. [CrossRef] 
21. Morgan, M.S. The World in the Model. How Economists Work and Think; Cambridge University Press: Cambridge, UK, 2012.

22. Callen, H.B. Thermodynamics and an Introduction to Thermostatistics, 2nd ed.; Wiley \& Sons: New York, NY, USA, 1985.

23. Fuchs, H.U.; Corni, F.; D'Anna, M. Entropy and the experience of heat. Nat. Entropy Its Direct Metrol. 2022, Forthcoming.

24. Fuchs, H.U. A surrealistic tale of electricity. Am. J. Phys. 1986, 54, 907-909. [CrossRef]

25. $\mathrm{Wu}, \mathrm{G}$.; $\mathrm{Wu}, \mathrm{Y}$. A new perspective of how to understand entropy in thermodynamics. Phys. Educ. 2020, 55, 015005. [CrossRef]

26. Fox, R. The Caloric Theory of Gases. From Lavoisier to Regnault; Clarendon Press: Oxford, UK, 1971.

27. Calendar, H.L. The Caloric Theory of Heat and Carnot's Principle. Proc. Phys. Soc. London 1911, 23, 153-189. [CrossRef]

28. Falk, G. Entropy, a resurrection of caloric-A look at the history of thermodynamics. Eur. J. Phys. 1985, 6, 108-115. [CrossRef]

29. Fuchs, H.U. Entropy in the teaching of introductory thermodynamics. Am. J. Phys. 1987, 55, 215-219. [CrossRef]

30. Mareš, J.J.; Hubík, P.; Šesták, J.; Špička, V.; Krištofik, J.; Stávek, J. Phenomenological approach to the caloric theory of heat. Thermochim. Acta 2008, 474, 16-24. [CrossRef]

31. Gentner, D. Structure-mapping: A theoretical framework for analogy. Cogn. Sci. 1983, 7, 155-170. [CrossRef]

32. Herrmann, F.; Wu, G.; Pohlig, M.; Fuchs, H.U.; D'Anna, M.; Rosenberg, J. Analogies: A Key to Understanding Physics. In Proceedings of the 2010 GIREP Conference on Physics Education, Reims, France, 22-27 August 2010.

33. Carnot, S. Réflexions sur la Puissance Motrice du Feu et Sur les Machines Propres à Développer cette Puissance. In Annales scientifiques de l'École Normale Supérieure; Bachelier: Paris, France, 1824; Volume 1, pp. 393-457.

34. Corni, F.; Fuchs, H.U.; Landini, A.; Giliberti, E. Visual and gestural metaphors for introducing energy to student teachers of primary school and kindergarten levels. J. Phys. Conf. Ser. 2019, 1287, 012043. [CrossRef]

35. Deichmann, M. Im übertragenen Sinne. Metaphern und Bildvergleiche in der Wissernschaft. Bachelor's Thesis, Zürcher Hochschule der Künste, Zurich, Switzerland, 2014. Available online: http:/ /vimeo.com/98311515 (accessed on 8 November 2021).

36. Johnson, M. The Body in the Mind; University of Chicago Press: Chicago, IL, USA, 1987.

37. Hampe, B. From Perception to Meaning: Image Schemas in Cognitive Linguistics; Mouton de Gruyter: Berlin, Germany, 2005.

38. Lakoff, G.; Johnson, M. Metaphors We Live By; University of Chicago Press: Chicago, IL, USA, 1980.

39. Lakoff, G.; Johnson, M. Philosophy in the Flesh; Basic Books: New York, NY, USA, 1999.

40. Grady, J. Foundations of Meaning: Primary Metaphors and Primary Scenes. Ph.D. Thesis, University of California, Berkeley, CA, USA, 1987.

41. Koevecses, Z. Metaphor: A Practical Introduction, 2nd ed.; Oxford University Press: Oxford, UK, 2010.

42. Contini, A. Metaphors, stories, and knowledge of the world. In Proceedings of the International Exploratory Workshop, Weissbad, Switzerland, 7-9 July 2015; Swiss National Science Foundation: Bern, Switzerland, 2015.

43. Amin, T.G.; Jeppsson, F.; Haglund, J. Conceptual metaphor and embodied cognition in science learning. Introduction to the special issue. Int. J. Sci. Educ. 2015, 37, 745-758. [CrossRef]

44. Fuchs, H.U.; Contini, A.; Dumont, E.; Landini, A.; Corni, F. How metaphor and narrative interact in stories of forces of nature. In Narrative and Metaphor in Education; Hanne, M., Kaal, A., Eds.; Routledge: London, UK, 2018.

45. Caracciolo, M. The Experientiality of Narrative; An Enactivist Approach de Gruyter: Berlin, Germany, 2014.

46. Fuchs, H.U.; Corni, F.; Dumont, E. Narrativity in complex systems. In Science I Environment I Health-Towards a Science Pedagogy of Complex Living Systems. Contributions from Science Education Research; Zeyer, A., Kyburz-Graber, R., Eds.; Springer: Cham, Switzerland, 2021.

47. Fuchs, H.U.; Dumont, E.; Corni, F. The power of forces of nature-How narrative introduces us to the notion of energy. In Proceedings of the Innovazione nella Didattica Delle Scienze nella Scuola Primaria: Al Crocevia fra Discipline Scientifiche e Umanistiche, Reggio Emilia, Italy, 1-2 February 2019. To be published.

48. Tyreus, B. Dominant Variables for Partial Control. 1. A Thermodynamic Method for their Identification. Ind. Eng. Chem. Res. 1999, 38, 1432-1443. [CrossRef]

49. Richards, D.E. Basic Engineering Science-A Systems, Accounting, and Modeling Approach; Rose-Hulman Institute of Technology: Terre Haute, IN, USA, 2001; Available online: https:/ / scholar.rose-hulman.edu/cgi/viewcontent.cgi?article=1722\&context= mechanical_engineering_fac (accessed on 8 November 2021).

50. Heron, P.R.L. Teaching goals for energy: What should students learn about what energy is? In Proceedings of the Roundtable Discussion at the GIREP-ICPE-EPEC Conference, Dublin, Ireland, 3-7 July 2017.

51. Lindsey, B.A.; Heron, P.R.L.; Shaffer, P.S. Student understanding of energy: Difficulties related to systems. Am. J. Phys. 2012, 80, 154-163. [CrossRef]

52. Scherr, R.E.; Close, H.G.; McKagan, S.B.; Vokos, S. Representing energy. I. Representing a substance ontology for energy. Phys. Rev. Spec. Top. Phys. Educ. Res. 2012, 8, 020114. [CrossRef]

53. Scherr, R.E.; Close, H.G.; Close, E.W.; Vokos, S. Representing energy. II. Energy tracking representations. Phys. Rev. Spec. Top. Phys. Educ. Res. 2012, 8, 020115. [CrossRef]

54. Kubsch, M.; Opitz, S.; Nordine, J.; Neumann, K.; Fortus, D.; Krajcik, J. Exploring a pathway towards energy conservation through emphasizing the connections between energy, systems, and fields. Discip. Interdiscip. Sci. Educ. Res. 2021, 3, 2. [CrossRef]

55. Close, H.G.; Scherr, R.E. Enacting Conceptual Metaphor through Blending: Learning activities embodying the substance metaphor for energy. Int. J. Sci. Educ. 2015, 37, 839-866. [CrossRef]

56. Keenan, J.H. Availability and Irreversibility in Thermodynamics. Br. J. Appl. Phys. 1951, 2, 183-192. [CrossRef]

57. Bejan, A. Advanced Engineering Thermodynamics; John Wiley \& Sons: New York, NY, USA, 1988. 
58. Corning, P.A.; Kline, S.J. Thermodynamics, Information and Life Revisited, Part I: 'To Be or Entropy'. Syst. Res. Behav. Sci. 1998, 15, 273-295. [CrossRef]

59. Amin, T.G. Conceptual Metaphor Meets Conceptual Change. Hum. Dev. 2009, 52, 165-197. [CrossRef]

60. Lancor, R. Using Metaphor Theory to Examine Conceptions of Energy in Biology, Chemistry, and Physics. Sci. Educ. 2014, 23, 1245-1267. [CrossRef]

61. Harrer, B.W. On the origin of energy: Metaphors and manifestations as resources for conceptualizing and measuring the invisible, imponderable. Am. J. Phys. 2017, 85, 454-460. [CrossRef]

62. Heron, P.R.L.; Michelini, M.; Stefanel, A. Teaching and Learning the Concept of Energy in Primary School. In Physics Curriculum Design, Development and Validation, GIREP 2008 Proceedings; Constantinou, C.P., Papadouris, N., Eds.; The Learning Science Group: Nicosia, Cyprus, 2009; Available online: http:/ / lsg.ucy.ac.cy/girep2008/intro.htm (accessed on 8 November 2021).

63. Heron, P.R.L.; Heylon, B.S.; Michelini, M.; Lehavi, Y.; Stefanel, A. Report of the workshop in GIREP Conference in FranceReims 2010 Teaching about Energy. Which Concepts should be Taught at Which Educational Level? Proceedings of The World Conference on Physics Education 2012, Istanbul, Turkey, 1-6 July 2012; Tasar, F., Ed.; Pegem Akademiel: Ankara, Turkey, 2014; pp. 519-530, ISBN 978-605-364-658-7. Available online: http://iupap-icpe.org/publications/proceedings/WCPE2012_ proceedings.pdf (accessed on 8 November 2021).

64. Falk, G.; Herrmann, F. Neue Physik. Das Energiebuch; Herrmann Schroedel Verlag KG: Hannover, Germany, 1981.

65. Fuchs, H.U. Modeling of Uniform Dynamical Systems; Orell Füssli: Zurich, Switzerland, 2002. Available online: http://www. hansfuchs.org/MUDS/MUDS_TOP.html (accessed on 8 November 2021).

66. Mariani, C.; Laurenti, E.; Corni, F. Hands-on, minds-on activities to construct the concept of energy in primary school: Experiments, games and group discussions. Lat. Am. J. Phys. Educ. 2012, 6, 105-111.

67. Mariani, C.; Corni, F.; Fuchs, H.U. A didactic approach to and curricular perspectives of the construction of the energy concept in primary school. In Proceedings of the GIREP-EPEC Conference 2011, Jyväskylä, Finland, 1-5 August 2012; Lindell, A., Kähkönen, A.-L., Viiri, J., Eds.; pp. 248-253.

68. Casey, E. Imagining: A Phenomenological Study; Indiana University Press: Bloomington and Indianapolis, IN, USA, 2000.

69. Falk, G.; Herrmann, F.; Schmid, G.B. Energy forms or energy carriers? Am. J. Phys. 1983, 51, 1074-1077. [CrossRef]

70. Hutto, D. The narrative practice hypothesis: Origins and applications of folk psychology. R. Inst. Philos. Suppl. 2007, 82, 43-68. [CrossRef]

71. Hutto, D. Folk Psychological Narratives; The MIT Press: Cambridge, MA, USA, 2008.

72. GDSU. Perspektiorahmen Sachunterricht; completely revised and extended edition; Verlag Julius Klinkhardt: Bad Heilbrunn, Germany, 2013.

73. Dumont, E.; Fuchs, H.U.; Corni, F.; Contini, A.; Altiero, T.; Romagnoli, M.; Karwasz, G.P. FCHgo: Fuel Cells HydroGen educatiOnal model for schools, an imaginative approach to hydrogen and fuel cell technology for young students and their teachers. J. Phys. Conf. Ser. 2021, 1229, 012019. [CrossRef]

74. Karwasz, G.; Wyborska, K.; Altiero, T.; Cesari, M.; Corni, F.; Dumont, E.; Fuchs, H.U.; Hagen, A. Fuel Cells Hydrogenm Educative Model Goes to Schools-First Results are Encouraging. In Proceedings of the 8th International Conference on Researh in Didactics of the Sciences DIDSCI 2020, Krakow, Poland, 17-19 June 2020.

75. Landini, A.; Giliberti, E.; Corni, F. The Role of Playing in the Representation of the Concept of Energy: A Lab Experience for Future Primary School Teachers. In Concepts, Strategies and Models to Enhance Physics Teaching and Learning; McLoughlin, E., van Kampen, P., Eds.; Springer: Berlin, Germany, 2019; pp. 125-137. [CrossRef]

76. Corni, F.; Dozza, L. Max's Worlds: An Innovative Project for K-6 Science Education. In Teaching-Learning Contemporary Physics, From Research to Practice; Jarosievitz, B., Sükösd, C., Eds.; Springer: Cham, Switzerland, 2021; pp. 237-249.

77. Pahl, A. Teaching Physics in Kindergarten and Primary School: What do Trainee Teachers Think of This? J. Phys. Conf. Ser. 2021, in press.

78. Pahl, A.; Tschiesner, R.; Adamina, M. The 'Nature-Human-Society'—Questionnaire: Psychometric Properties and Validation. ICERI2019 Proc. 2019, 12, 3196-3205. [CrossRef]

79. Tschiesner, R.; Pahl, A. Trainee Teachers' Preferences in the Subject 'Nature-Human-Society': The Role of Knowledge. ICERI2019 Proc. 2019, 12, 3167-3176. [CrossRef]

80. Corni, F.; Giliberti, E.; Fuchs, H.U. Student Teachers Writing Science Stories: A Case Study. In Proceedings of the ESERA 2013-Science Education Research for Evidence-Based Teaching and Coherence in Learning, Nicosia, Cyprus, 2-7 September 2013; Constantinou, C.P., Papadouris, N., Hadjigeorgiou, A., Eds.; 2014; pp. 2494-2505.

81. Spreckelsen, K. Phänomenkreise als Verstehenshilfen. In Kinder auf dem Weg zum Verstehen der Welt; Köhnlein, W., Marquardt-Mau, B., Schreier, H., Eds.; Klinkhardt: Bad Heilbrunn, Germany, 1997; pp. 111-127.

82. Pahl, A. Diagnostik und Förderung Naturwissenschaftlicher Kompetenzen Durch Differenzierte Experimentiereinheiten; Cuvellier: Göttingen, Germany, 2015.

83. Herman, D. Basic Elements of Narrative; Wiley-Blackwell: Chichester, UK, 2009.

84. Kleickmann, T. Kognitiv Aktivieren und Inhaltlich Strukturieren im Naturwissenschaftlichen Sachunterricht; IPN Leipniz-Institut für die Pädagogik der Naturwissenschaften und Mathematik an der Universität Kiel: Kiel, Germany, 2012.

85. Pahl, A. Research Methods for Investigating Young Children's Learning with Science Experiments-An overview. ICERI2019 Proc. 2019, 12, 3177-3186. [CrossRef] 